\title{
Multiple Sclerosis and Obesity: Possible Roles of Adipokines
}

\author{
José de Jesús Guerrero-García, ${ }^{1,2}$ Lucrecia Carrera-Quintanar, ${ }^{2}$ \\ Rocío Ivette López-Roa, ${ }^{3}$ Ana Laura Márquez-Aguirre, ${ }^{4}$ \\ Argelia Esperanza Rojas-Mayorquín, ${ }^{5}$ and Daniel Ortuño-Sahagún ${ }^{2}$
}

\author{
${ }^{1}$ U.M.A.E. Hospital de Pediatría, C.M.N.O., Instituto Mexicano del Seguro Social, Guadalajara, JAL, Mexico \\ ${ }^{2}$ Instituto de Investigación en Ciencias Biomédicas (IICB), CUCS, Universidad de Guadalajara, Guadalajara, JAL, Mexico \\ ${ }^{3}$ Departamento de Farmacobiología, CUCEI, Universidad de Guadalajara, Guadalajara, JAL, Mexico \\ ${ }^{4}$ Unidad de Biotecnología Médica y Farmacéutica, Centro de Investigación y Asistencia en Tecnología y Diseño del Estado de \\ Jalisco A. C., Guadalajara, JAL, Mexico \\ ${ }^{5}$ Departamento de Ciencias Ambientales, Instituto de Neurociencias, CUCBA, Universidad de Guadalajara, Guadalajara, JAL, Mexico
}

Correspondence should be addressed to Daniel Ortuño-Sahagún; daniel.ortuno.sahagun@gmail.com

Received 26 May 2016; Revised 22 July 2016; Accepted 8 August 2016

Academic Editor: José César Rosa Neto

Copyright ( 92016 José de Jesús Guerrero-García et al. This is an open access article distributed under the Creative Commons Attribution License, which permits unrestricted use, distribution, and reproduction in any medium, provided the original work is properly cited.

\begin{abstract}
Multiple Sclerosis (MS) is an autoimmune disorder of the Central Nervous System that has been associated with several environmental factors, such as diet and obesity. The possible link between MS and obesity has become more interesting in recent years since the discovery of the remarkable properties of adipose tissue. Once MS is initiated, obesity can contribute to increased disease severity by negatively influencing disease progress and treatment response, but, also, obesity in early life is highly relevant as a susceptibility factor and causally related risk for late MS development. The aim of this review was to discuss recent evidence about the link between obesity, as a chronic inflammatory state, and the pathogenesis of MS as a chronic autoimmune and inflammatory disease. First, we describe the main cells involved in MS pathogenesis, both from neural tissue and from the immune system, and including a new participant, the adipocyte, focusing on their roles in MS. Second, we concentrate on the role of several adipokines that are able to participate in the mediation of the immune response in MS and on the possible cross talk between the latter. Finally, we explore recent therapy that involves the transplantation of adipocyte precursor cells for the treatment of MS.
\end{abstract}

\section{Introduction}

The prevalence of immune-mediated diseases has increased in recent years. In parallel, changes in dietary habits, which promote high-fat, high-sugar, and high-salt foods, have led to an obesity epidemic over the past years $[1,2]$. According to the World Health Organization (WHO), approximately $35 \%$ of the world population is estimated to have overweight (Body Mass Index [BMI], $25-30 \mathrm{~kg} / \mathrm{m}^{2}$ ) or obesity (BMI > $30 \mathrm{~kg} / \mathrm{m}^{2}$ ) [3]. Therefore, it is reasonable to think about a possible correlation among these realities. In fact, obesity is considered a chronic state of low-grade inflammation that has been implicated as a proactive factor in several chronic autoimmune inflammatory disorders $[4,5]$.

Multiple sclerosis (MS) is an autoimmune disorder of the Central Nervous System (CNS), which is mainly characterized by selective and coordinated inflammatory destruction of myelin, with damage to the axon. It is a chronic and progressive inflammatory disease caused by an interaction of genetic and environmental risk factors. MS mainly affects young people with onset usually at the age of 20-50 years and a mean age-of-onset of 30 years, although the disease may also develop in childhood and after the age of 60 years [6]. Childhood and adolescence are thought to be a critical period of susceptibility to promoting factors.

This autoimmune disease has already been associated with several environmental factors, such as diet and obesity [7-10]. Obesity is a well-known risk factor for multiple conditions, including cardiovascular risk and metabolic disorders, as metabolic syndrome and insulin resistance [11], and has also been associated with a nonfavorable course of several autoimmune diseases [2]. Concomitant with the rise of MS 
is the increased prevalence of children with overweight and obesity in human population over recent decades [3].

Several studies have reported an increase in the prevalence of overweight and obesity among patients with MS [12], although some reported higher frequencies of patients with MS with a lower BMI [13] and some others reported similar rates of overweight and obesity in patients with MS and in general population [14]. Numerous publications have reported an association between MS and higher BMI in youth and early life [15-19]. Obesity in female patients with MS at the time of diagnosis is associated with a relapsing course at disease onset [20] and is also associated with a greater risk of depression, lower functional capacity, and worse self-rated health status among patients with MS [21, 22]. However, a direct relationship between MS and obesity remains inconclusive [23].

A reported cooccurrence of obesity in patients with MS may simply reflect increased obesity in the population or it may be secondary to the harmful effects of the disease. However, a positive correlation between BMI and disability evaluated by the Expanded Disability Status Scale (EDSS) was reported recently [24]. To date, scarce information is available on the association of metabolic comorbidities and disability in individuals with MS. One study [25] showed that vascular comorbidities, such as diabetes, hypertension, hypercholesterolemia, and peripheral vascular disease, were independently associated with an increased risk for disability. In contrast, another study reported that worsening disability was associated with higher low-density lipoprotein cholesterol, total cholesterol, and triglycerides in patients with MS [26]. Additionally, an association exists between disability and Oxidative Stress (OS) in patients with MS [27]. What is becoming clear is that obesity influences both disease progress and treatment response. Additionally, a couple of recent studies in large populations clearly associate obesity in early life, during adolescence [28], and during childhood and/or early adulthood [29] with a higher MS risk, providing further solid evidence strongly suggesting that obesity is also relevant by means of its causal role in MS etiology.

The possible link between MS and obesity has become even more interesting in recent years since the discovery of the remarkable properties of adipose tissue. Adipose tissue has the ability to expand in response to chronic caloric excess as an adaptive response. In individuals with obesity, adipose tissue can constitute up to $50 \%$ of total body mass. Since the exciting finding of the secretory properties of adipose tissue, the relationship between obesity and autoimmunity and the understanding of the underlying mechanisms have become of major interest. Indeed, fat tissue, in addition to its function as an energy storage site, has been found to produce a wide variety of soluble mediators denominated "adipokines," which are involved in the regulation of numerous physiological functions, such as the regulation of energy balance, insulin sensitization, and the immune response [2]. Initially identified for their metabolic and appetite regulation activities, adipokines are known to be involved in various processes, including immunity and inflammation. Because of their proinflammatory action, these molecules contribute to the so-called "low-grade inflammatory state" in subjects with obesity [30].

Obesity is associated with self-directed tissue inflammation, in which local or systemic factors other than infectious agents activate the cells of the innate immune system. During the development of obesity, adipocytes undergo considerable differentiation and expansion in order to store lipids [31]. However, immune cell infiltration and activation within adipose tissue are a major source of proinflammatory cytokines, which impair adipocyte function in chronic obesity. Thus, alterations in adipose tissue and the development of chronic inflammation are the hallmarks of obesity and are at least partially responsible for the induction of insulin resistance.

On this basis, the aim of this review was to present, integrate, and discuss recent evidence on the possible link between obesity as a chronic inflammatory state and the pathogenesis of MS as a chronic autoimmune and inflammatory disease. First, we briefly describe the main cells involved in MS pathogenesis, both from neural tissue, including glial cells (such as microglial cells, oligodendrocytes, and astrocytes) and neurons, as well as cells from the immune system such as different $\mathrm{T}$ cell lineages, CD4+ (such as Th1, Th2, and Th17), CD8+, and Treg (CD4+CD25+FoxP3+), and also including a new participant, the adipocyte, a cell from the adipose tissue, focusing on their roles in MS. Second, we concentrate on the role of several adipokines that are able to participate in the mediation of the immune response in MS and on the possible cross talk between these. Finally, we explore recent therapy that involves the transplantation of adipocyte precursor cells for the treatment of MS.

\section{Cells Involved in MS}

\subsection{CNS Cells}

2.1.1. CNS: Microglia. Microglia constitute the resident macrophages of the CNS [40] and are involved in immune processes as such as Antigen Presenting Cells under pathological conditions [41]. Microglia express several immunological markers, such as MHC I, MHC II, CD40, CD11b, Fc receptors I-III, Complement Receptors (CR1, CR2, and CR4), $\beta 2$ integrins, CD80, CD86, and IntraCellular Adhesion Molecule-1 (ICAM-1) [42]. Dual roles of macrophages have been described in human neuroimmune diseases such as MS. Whereas proinflammatory macrophages secrete harmful molecules to induce disease development, anti-inflammatory macrophages produce beneficial mediators to promote disease recovery [43].

In experimental autoimmune encephalomyelitis (EAE) in mice, an animal model for MS, the expressions of MHC II and CD86 are increased (Table 1). This suggests that microglia participate in the antigen presentation to the $\mathrm{T}$ cells that migrate into the CNS. In addition, in MS lesions, microglia and CNS-infiltrating macrophages interact with oligodendrocytes by their expression of VCAM-1 [44] and with phagocyte myelin and axon debris, via HLA-DR, contributing to the demyelination process [45].

The activation of microglia in MS is a dynamic process, because there is an intermediate state in all preactive and 
TABLE 1: Cell types affected in the experimental autoimmune encephalomyelitis (EAE) mouse model or in patients with multiple sclerosis (MS).

\begin{tabular}{|c|c|c|c|}
\hline Adipokine & EAE & Multiple sclerosis & Reference \\
\hline \multirow{4}{*}{ Leptin } & & $\begin{array}{l}\downarrow \text { IFN- } \gamma \text { - and IL-17-secreting T cells in patients treated } \\
\text { with Metformin } \\
\downarrow \text { TNF- } \alpha \text { - and IL-6-secreting T cells in patients treated } \\
\text { with Pioglitazone } \\
\uparrow \text { CD4+CD25+FoxP3 Treg in patients treated with } \\
\text { Metformin and Pioglitazone }\end{array}$ & [72] \\
\hline & & $\begin{array}{l}\downarrow \text { NK cells, } \downarrow \text { B cells, } \downarrow \text { CD } 4+D R+T \text { cells, and } \downarrow \\
\text { CD4+CD45RA }+ \text { T cells in patients treated with GA }\end{array}$ & [73] \\
\hline & & $\downarrow$ nTreg cells in patients with RRMS & {$[74]$} \\
\hline & $\begin{array}{l}\downarrow \mathrm{CD} 4+\mathrm{T} \text { cells, CD8+ T cells, and CD11b+Grl+ } \\
\text { granulocytes in ENdothelial leptin receptor-specific } \\
\text { Knock-Out (ENKO) }\end{array}$ & & {$[32]$} \\
\hline Adiponectin & $\begin{array}{l}\text { Adiponectin treatment is associated with increase in } \\
\text { Treg }\end{array}$ & & {$[36]$} \\
\hline
\end{tabular}

remyelinating lesions that differ from microglia profiles in actively demyelinating lesions [46]. Antigen-activated microglia produce proinflammatory cytokines, such as InterLeukin-1beta (IL-1 $\beta$ ), Tumor Necrosis Factor alpha (TNF- $\alpha$ ), and IL-6 [42]. A subset of CD4+ T cells that produces IL-17 or IL-17 and InterFeroN gamma (IFN- $\gamma$ ) migrates to the CNS prior to the onset of EAE clinical symptoms (revised forward). This event coincides with microglia activation and their production of IL- $1 \beta$, TNF- $\alpha$, and IL- 6 in the CNS [47]. Treatment with Glatiramer Acetate (GA) prevents interaction between $\mathrm{T}$ cells and microglia and contributes to the amelioration of MS severity in patients [48]. These facts support that, in the pathogenesis of MS, both peripheral immune system cells and CNS resident cells are involved from disease onset.

In a recent study, Michels et al. demonstrated, in an animal model of sepsis, that costimulation of microglia through CD40-CD40L is associated with brain inflammation, oxidative damage, and Blood Brain Barrier (BBB) dysfunction [49]. In addition, soluble CD40L has been associated with the complications of obesity, such as cardiovascular disease, insulin resistance, and chronic inflammation [50]. CD40 is a transmembrane receptor expressed in a variety of cell types including microglia in the CNS [49]. The interaction between CD40 and its ligand (CD40L), expressed by $\mathrm{T}$ cells, induces costimulation in the presenting antigen and enhances the production of cytokines, chemokines, matrix metalloproteinases, growth factors, and adhesion molecules, mainly through NF- $\kappa \mathrm{B}$ [51]. Also, the presence of CD40L plus IFN- $\gamma$ induces ERK1/2-mediated Monocyte Chemoattractant Protein-1 (MCP-1) and p38-mediated IFNInducible Protein-10 (IP-10) production by microglia. These chemokines have been associated with CNS pathologies, including MS [52]. It is possible that CD40/CD40L interactions between microglia/macrophages and $\mathrm{T}$ cells are involved in MS pathogenesis; thus, future studies should be conducted on this aspect.

Regarding microglia cells participation in axonal damage, activated microglia releases glutamate, which induces excitotoxicity and contributes to damage. Blockade of glutamate release decreases neuronal death [53]. In this respect, higher levels of glutaminase, produced by macrophages and microglia, are found in MS lesions, and these levels are correlated with axonal damage in animals. In addition, GLutamate Transporter-1 (GLT-1) has low expression levels in active lesions, and Glutamine Synthetase (GS) and Glutamate DeHydrogenase (GDH) are absent in active and chronic, silent MS lesions [54]. This glutamate unbalance leads to neural death and increases CNS damage and disease severity.

Microglia can not only be involved in the inflammatory and neurodegenerative process. It is possible to induce a neuroprotective state in the microglia through a stimuli with IL-4 and IL-25 [55]. This neuroprotective state can induce oligodendrogenesis through its activation by IL- 4 and IFN- $\gamma$ and a later release of Insulin-Like Growth Factor1 (IGF-1) [56]. Additionally, intraparenchymal microglia produce a Macrophage-Derived Chemokine (MDC/CCL22), which could induce Th2 cell migration into the CNS and mediate Th1-migration [57]. Furthermore, Programmed Death-Ligand-1 (PD-L1) acts as an inhibitory costimulatory molecule that is expressed by microglia after stimulation with IFN- $\gamma$ [58] or IL-6 [59], and CNS-infiltrating T cells exhibit overexpression of their receptor Programmed Death1 (PD-1) at the EAE peak and prior to remission. In this regard, microglia can inhibit CD4 $+\mathrm{T}$ cell proliferation and Th1 cell differentiation in a PD-L1-dependent manner [41]. Therefore, microglia can play a dual role in the pathogenesis of MS, depending on the cytokine microenvironment, where it can perform inflammatory functions that promote axonal damage and neural death or anti-inflammatory functions that inhibit cell migration into the CNS.

In vitro, Peroxisome Proliferator-Activated Receptor gamma (PPAR- $\gamma$ ), a regulator of adipocyte differentiation implicated in obesity [60], is strongly upregulated following demyelination mediated by antibodies directed against the Myelin Oligodendrocyte Glycoprotein (MOG) in the presence of complement [61]. Pioglitazone, an agonist of PPAR- $\gamma$ that modulates the transcription of insulin-sensitive 
genes [62], partially protects aggregates from anti-MOG demyelination, and it appears to be linked with an inhibition of glial cell proinflammatory activities following anti-MOGinduced demyelination [61]. Additionally, a similar effect to that of pioglitazone can be provided by nutraceutics, which can modulate PPAR- $\gamma$ signaling and which can be employed as a complimentary treatment for obesity-related disorders [63]. Activation of PPAR- $\gamma$ signaling regulates adiponectin production, a protein with anti-inflammatory properties trough the inhibition of proinflammatory cytokines and a protective role against insulin resistance [64]. PPAR- $\gamma$ agonists can modulate EAE by the inhibition of NO, TNF$\alpha$, IL- $1 \beta$, IL-6, and MCP-1 production from microglia and astrocytes [65] and also by inhibiting IL-12 production and signaling and Thl differentiation [66]. In addition, it has been demonstrated that Steroid Receptor Coactivator-3 (SRC-3) inhibits adipocyte differentiation [67] and controls the expression of PPAR. SRC-3 deficiency attenuates EAE severity through the upregulation of PPAR- $\beta$ in the CNS and the subsequent microglia-alternative activation, which modulates neuroinflammation and promotes remyelination [68]. Together, these data suggest that the PPAR agonist could modulate the demyelination process in EAE and MS.

On the other hand, microglia express estrogen receptor$\beta$, and their signaling reduces NF- $\kappa \mathrm{B}$ expression, as well as NF- $\kappa$ B-induced gene-inducible Nitric Oxide Synthase (NOS) in microglia and CD3+ T cells [69]. It has been demonstrated that $\mathrm{T}$ cells induce microglia activation through C/EBPbeta, but not NF- $\kappa \mathrm{B}$, in EAE, but only in female mice. This is one of the mechanisms that could explain why MS is more prevalent in women [70]. Also, estrogen pretreatment in EAE mice enhanced the frequency of regulatory $B$ cells and antiinflammatory M2 microglia [71]. These evidences suggest that estrogen treatment promotes neuroprotection through the inhibition of $\mathrm{T}$ cell and macrophage recruitment into the CNS and microglia activation, which may represent a benefit for MS treatment.

2.1.2. CNS: Oligodendrocytes. Oligodendrocytes are the myelinating cells of the CNS. Both neurons and oligodendrocytes are affected during brain damage in acute and chronic neuroinflammation, leading to demyelination processes [102]. In MS, oligodendrocytes are damaged by different processes and their number decreases. Oligodendrocyte Precursor Cells (OPC) are present in both normal CNS and MS lesions [103]. There is evidence indicating changes in the mechanisms of migration of OPC and myelinating oligodendrocytic activity. In this sense, Bin et al. found that netrin-1, an inhibitor of Oligodendrocyte Precursor Cell migration, is secreted by myelinating oligodendrocytes in MS lesions [104]. In addition, Sádaba et al. demonstrated the presence of IgM and IgG in demyelinating lesions localized in axons and oligodendrocytes from the autopsies of patients with MS [105]. However, the presence of Platelet-Derived Growth factor alpha Receptor (PDGRalphaR) and NG2 OPC in active MS lesions, as in remyelinated MS tissue, indicates that these cells are potential sources of remyelinating oligodendrocytes in active lesions [106]. Furthermore, the expression of CD200 in neurons, oligodendrocytes, and reactive astrocytes in MS chronic plaques and the interaction with its receptor CD200R suppress immune activity [107], and this affects neuronmicroglia and glia-glia interactions.

In an attempt to prevent this damage, it has been reported that oligodendrocytes stimulated with IFN- $\gamma$, a proinflammatory cytokine, could be protected. Pancreatic Endoplasmic Reticulum Kinase (PERK) signaling can be activated in oligodendrocytes in the presence of IFN- $\gamma$ in MS lesions [108]. The activation of PERK signaling pathway in oligodendrocytes attenuates EAE severity by a reduction of oligodendrocytic apoptosis and demyelination [109], indicating that activation of an integrated stress response could ameliorate MS severity.

2.1.3. CNS: Astrocytes. Astrocytes are the most abundant type of cells in the CNS. They participate in maintaining normal brain function and are in constant communication with neurons, oligodendrocytes, and Endothelial Cells. Also, astrocytes are involved in angiogenesis, neurogenesis, synaptogenesis, and axonal remodeling [110]. However, B71 (CD80) or B7-2 (CD86) is not expressed by astrocytes and CNS Endothelial Cells (EC) in EAE. This suggests that neither type of these cells can induce costimulatory signals via B7 molecules and that they are incapable of acting as Antigen Presenting Cells (APC) [111].

It has been demonstrated that astrocytes are involved in the progress of MS through several mechanisms, which include the following: releasing cytotoxic factors, inhibiting axonal remyelination, and contributing to axonal mitochondrial dysfunction [112]. In this regard, neuregulin production, an oligodendrocytic growth factor, is depleted in astrocytes [113], leading to the decrease of the oligodendrocytic maturation ability. Also, CD24 is expressed in both immune and CNS cells. Liu et al. demonstrated that CD24 expression enhanced costimulatory activity of astrocytes with T cells and increased EAE severity [114]. Furthermore, astrocytes and microglia can express inducible NO Synthase (iNOS) in EAE lesions [115], which contributes to axonal damage [116]. These data demonstrate the relevant contribution of astrocytes to MS pathogenesis and progression.

2.1.4. CNS: Neurons. The immune-mediated destruction of CNS myelin and oligodendrocytes has traditionally been considered the primary damage in patients with MS; however, the irreversibility of the neurological disability corresponds to cortical damage, driven by either neuronal loss induced by retrograde degeneration from white-matter lesions or as a direct consequence of the localization of demyelinated plaques within the cortex [117]. Main damage to neurons derives from the demyelination process, which affects myelin sheaths as well as the oligodendrocyte itself [118].

The profound oxidative injury observed in MS lesions appears to be related to mitochondrial impairment in damaged axons [119]. Consistently, synaptic loss comprises a characteristic feature of gray matter lesions (particularly in type I lesions) [120], and neurite density is proportionally reduced with increased meningeal inflammation [121]. Neurons can also interact with $\mathrm{CD} 4+\mathrm{T}$ cells and induce its differentiation into CD25+ TGF-betal+ CTLA-4+ FoxP3+ 
Treg through the interaction between the B7-CD28 and TGF-betal-TGF-beta receptor signaling pathways. These Treg suppress encephalitogenic T cells in a CTLA-4 manner [122]. This data indicates that neurons can execute mechanisms that attempt to reverse the damage in the demyelination process.

\subsection{Immune System Cells}

2.2.1. Immune System: T Cells. T cells are a highly heterogeneous population of cell subtypes that mediate adaptive immunity and specific tolerance [123]. There are several subpopulations of $\mathrm{T}$ cells that differentiate upon encountering antigens in the peripheral lymphoid organs [124]. In MS, the role of $\mathrm{T}$ cells is crucial to trigger the immunopathological processes that culminate in demyelination and subsequent damage to oligodendrocytes and axons [125]. Several studies demonstrate that pathogenic $\mathrm{T}$ cell response against myelin antigens is followed by a neurodegenerative process [126]. However, it is difficult to establish a correlation between CNSinfiltrating and peripheral T cell subsets. In this respect, it is necessary to consider the possible existence of subgroups of patients, depending on treatment and time of disease evolution [127] to identify the correlations of these subgroups with variations in the T cell subsets present in MS pathogenesis.

2.2.2. Immune System: CD4+ T Cells. CD4+ T cells could play a central role in the pathogenesis of the EAE model. These cells cross the $\mathrm{BBB}$ and cause axonal damage and neuronal death [128]. Within the CNS, microglial cells interact with T cells by antigen presentation and the production of injurious or neurotrophic outcomes in their vicinity [129]. Additionally, activation of memory CD4+ T cells is associated with the exacerbation of MS; in addition, activation of memory CD8+ $\mathrm{T}$ cells (see later) reflects a dysregulation of the immune system in patients with MS [130]. Full activation and posterior proliferation of $\mathrm{T}$ cells usually require an Antigen Presenting Cell- (APC-) derived costimulatory signal, which is delivered via $\mathrm{B} 7 / \mathrm{CD} 28$ [131]. However, the T cell proliferative response in MS is relatively independent of B7-CD28 costimulation [132-134].

Additionally, autoreactive T cells against myelin components can be detected in both the serum and CerebroSpinal Fluid (CSF) of patients with MS [135]. Burns et al. described that $84 \%$ of the MBP-reactive $\mathrm{T}$ cells are memory $\mathrm{T}$ cells in peripheral blood [136] but, according to Chou et al., only $37 \%$ of T cells isolated from patients with MS are MBP- or PLP-reactive in LCR [137]. Furthermore, CD4+ T cells in CSF are predominantly helper inducers, and their increase may contribute to local autoimmune process in the CNS [138]. Taken together, these studies prove that $\mathrm{T}$ cells reactive to myelin play an important role in the pathogenesis of MS.

2.2.3. Immune System: Th1 and Th2. Th1 cells secrete high levels of IFN- $\gamma$ and IL-12, which are considered proinflammatory cytokines. On the other hand, Th2 cells secrete high levels of anti-inflammatory cytokines, mainly IL-4, IL-5, IL-9, and IL-13, and promote the humoral response [139].
Originally, MS was considered as an autoimmune disease, driven by Thl cells. This was supported by three facts: (1) CD4+ T cells isolated from CNS from mice with EAE express detectable levels of IFN- $\gamma$ messenger RNA (mRNA) [140]; (2) IL-12p40-defective (IL-12p40-/-) mice are resistant to EAE induction, because IL-12 is a requirement for naïve T cell differentiation in Th1 cells [141]; and (3) patients with MS exhibited exacerbation during treatment with IFN- $\gamma$ [142]. However, several studies suggest that there is a dysregulation in the balance between Th1 and Th2 cytokine profiles in MS [143].

The Transforming Growth Factor-Beta (TGF- $\beta$ ) inhibitor Smad7 is an important negative modulator that regulates the strength of TGF- $\beta$ signaling [144] and it is upregulated in peripheral CD4+ T cells from patients with MS during disease relapse, but not during remission. This Smad7 expression correlates with T-beta responses, suggesting that Smad7 drives Thl differentiation and regulates the inflammatory cellular response [145]. Additionally, disease progression can be altered by a hormonal component that modifies $\mathrm{T}$ cell number and cytokine secretion. In this sense, CD4+ IFN- $\gamma$ producing cells fluctuate with MS relapses: declining during pregnancy, in women with MS, and continuing to decline after parturition, in women with relapses. In contrast, these cells rise, or remain stable, in women with nonrelapsing MS or healthy pregnant women [146].

In contrast, Th2 cells have been described as being protective in MS/EAE [147]. Th2 cells are able to suppress microglial activation via cell-to-cell contact [148]. Furthermore, treatment with GA, which shifts the cytokine profile from Th1 to Th2, is regularly utilized as immunomodulatory therapy for MS $[149,150]$. This suggests that Th2 cells are activated by GA in the periphery, migrate into the CNS, and then produce the Th2 cytokine profile after local recognition of Myelin Basic Protein (MBP) [150]. In the case of other treatments, patients with MS treated with IFN- $\beta$ showed downregulation of circulating T cells secreting IFN- $\gamma$ and IL4 [151].

However, despite the anti-inflammatory behavior of Th2 cells in autoimmune diseases, in a recent work, Planas et al. identified clonally expanded CD4+ T cells releasing Th2 cytokines in $\mathrm{T}$ cell infiltrate of pattern II brain autopsy lesions, and the authors argue that this subset possesses a pathogenic and not a protective role in MS [152].

It is noteworthy that Th1 and Th2 cells infiltrate adipose tissue which varies according to regional fat depot. Th1 cells are higher in Visceral Adipose Tissue (VAT) than in Subcutaneous Adipose Tissue (SAT) and peripheral blood in healthy individuals with overweight and obesity. However, these proinflammatory $\mathrm{T}$ cell frequencies in VAT are correlated with SAT and peripheral blood [153]. This suggests that peripheral $T$ cell subsets could also be associated with adipose tissue-infiltrating T cells in patients with MS and with obesity.

2.2.4. Immune System: Th17. The T-helper 17 (Th17) cells are a subset of CD4+ effector $\mathrm{T}$ lymphocytes that challenges the Th1/Th2 paradigm of the immune response. Th17 cells mainly secrete IL-17 and are currently recognized for their 
involvement in the pathogenesis of autoimmune diseases $[154,155]$.

In the CSF of patients with Relapsing-Remitting Multiple Sclerosis (RRMS), Th17 cell frequency is higher in the relapse than in the remission stage or than in other noninflammatory neurological diseases [156]. In acute lesions, the expression of Retinoic Acid-Related Orphan nuclear hormone Receptor (RORc) and the cytokine genes that participate in Th17 expansion are upregulated in acute autopsy lesions of patients with RRMS [157]. Because Th17 promotes BBB disruption and causes the increase of CD4+ T cell infiltration in the CNS [158], the presence of Th17 cells in the CNS is able to give rise to microglial activation and the increase of the proinflammatory cytokine microenvironment [47]. Furthermore, IL17, a cytokine produced mainly by Th17 cells, induces higher production of glutamate, causing excitotoxicity [159]. This cytokine has been investigated in autoimmune diseases [160], including MS [161].

Th17 cells can be influenced by the cytokine microenvironment, being able to exhibit certain developmental plasticity by upregulating IFN- $\gamma$ and T-bet with a decreasing expression of IL-17 and ROR $\gamma \mathrm{t}$ [162]. Additionally, Carbajal et al. demonstrated that plastic Th17 cells can also be mediators of demyelination and axonal damage, as well as of Thl, and can induce the classical features of MS independently of differentiation factors IL-23 and IL-12 [163]. These evidences indicate that there is a possible link between Th1- and Th17-mediated autoimmune demyelinating processes, which can provide a future, common therapeutic target for MS treatment.

The search for serum biomarkers that describe the behavior of MS includes the study of cytokines such as IL-17. However, it is difficult to correlate these levels with the evolution of the disease. Thus, the existence could be considered of subgroups of patients with specific characteristics, considering age, treatment, and time to disease progression [127]. In this respect, it would be possible for $\mathrm{T}$ cell subsets to also vary according to these subgroups in patients with MS.

Regarding treatment, IFN- $\beta$ induces greater STAT1 activation in Th17 compared to Th1 because Th17 cells express higher levels of InterFeroN alpha/beta Receptor 1 (IFN$\alpha / \beta \mathrm{R} 1)$. This result indicates that IFN $-\beta$ can inhibit Th17 cell expansion [164]. Therefore, IFN- $\beta$ suppresses Th17 differentiation in vitro by inhibiting Th17 cell-lineage markers RORc, IL-17A, IL-23, and CCR6 and by inducing IL-10 production $[165,166]$.

Recently, it was reported that obesity may predispose induction of Th17 cells, at least, in part, in an IL-6-dependent process, which exacerbates autoinflammatory diseases such MS in mouse models [167]. Paradoxically, IL-17 has also been shown to inhibit adipogenesis [168]. Therefore, the precise role of Th17 cells and IL-17 in the obesity-associated inflammatory conditions needs to be further clarified.

2.2.5. Immune System: $C D 4+C D 25+F o x P 3+$ Treg. Regulatory $\mathrm{T}$ cells (Treg) comprise specialized suppressor $\mathrm{T}$ cell population that restrains the pathogenic immune response [169], while CD4+CD25+FoxP3+ Treg maintain tolerance to self-antigens [170]. Treg mediate the autoimmune inflammation induced in EAE through Cytotoxic T Lymphocyte Antigen- (CTLA-) 4-dependent suppression of pathogenic $\mathrm{T}$ cells [122]. Posterior recovery correlates well with the accumulation of Treg, that are producers of IL-10 [171]. In MS, the Treg function is defective and this contributes to the pathogenesis of the disease [170]. Also, Treg are capable of migrating across the BBB under noninflammatory conditions but, in patients with RRMS, this ability is impaired [172]. This change contributes to breaking the homeostasis in the CNS and could facilitate the initiation of CNS inflammation.

The suppressor activity of $\mathrm{T}$ cells in the peripheral blood of patients with patients in remission-clinical-phase was first described by Huddlestone and Oldstone [173]. Since that time, controversial results have been reported concerning the presence of Treg during the fluctuating behavior of MS. In this regard, the frequency of CD4+CD25+FoxP3+ Treg was described as lower in patients with MS than in healthy controls [174, 175], but there was no correlation with clinical variables [174]. Bach et al. previously described that these cells are depressed in patients with acute exacerbation of MS [176]. Contrariwise, Dalla Libera et al. demonstrated that Treg are restored during an acute clinical attack [177]. This suggests that Treg are not involved in causing clinical relapses, but, rather, they can react to the inflammation in an attempt to restore the balance.

Regarding treatment, Praksova et al. described that both IFN- $\beta$ and GA increase naïve T cells and decrease central memory $\mathrm{T}$ cells [175], but only Glatiramer Acetate (GA) increases Treg $[175,178]$. However, this is in contrast with other works reporting that $\mathrm{CD} 4+\mathrm{CD} 25+\mathrm{FoxP} 3+$ Treg are increased in patients with MS treated with IFN- $\beta[179,180]$, without any significant effect on FoxP3 gene expression after 6 months [180]. It has been described that IFN- $\beta$ induces downregulation of CTLA-4 in Treg [179]. With respect to treatment effect, it has not been possible to date to establish any relationship between obesity and the use of $1 \mathrm{FN}-\beta$ or GA [181].

On the other hand, glucocorticoid treatment restores impaired Treg function and increases IL-10 production in relapsing patients with MS [182]. Further, glucocorticoids modulate T-bet and STAT1 expression in mononuclear cells from patients with RRMS [183]. The effect of glucocorticoid treatment contributes to the decrease of neuroinflammation. However, the chronic use of glucocorticoids is associated with weight gain and increased obesity and related disorders $[184,185]$.

With respect to sexual hormones, these appear to be involved in the increase of Treg, as well as other T cell populations. It has been described that, during gestation, there is a physiological expansion of Treg that contribute to decreasing EAE manifestations and reducing CNS demyelination [186]. In addition, E2 and P2 enhance Treg function in vitro [187], leading to the suggestion that the use of $\mathrm{E} 2$ is capable of being a therapy for MS $[188,189]$ but that estrogens participate in metabolic functions and their use in humans produces the accumulation of subcutaneous fat [190] which could trigger obesity and metabolic disorders. 
2.2.6. Immune System: CD8+ T Cells. Because the study of the immunological basis involved in MS has focused mainly on CD4+ T cells as mediators of the disease [191, 192], the role of CD8+ T cells in MS is unclear to date. However, CD8+ T cells constitute the predominant $\mathrm{T}$ cell population in lesions in patients with MS and are oligoclonally expanded at the site of the pathology [192]. Furthermore, it has been recently demonstrated that CD8+ T cells engage in both roles: the pathogenic and the regulatory role in MS [192].

CD8+ T cells and CD4+ T cells exhibit different epigenetic signatures because they have distinct DNA methylation profiles [193]. It has been demonstrated that myelin-specific CD8+ T cells infiltrate the CNS and play a pathogenic role in EAE. In addition, the presence of CD4+ T cells is required for more severe disease and sustained neuroinflammation [194]. Furthermore, CD8+ T cells participate in myelinspecific CD4+ differentiation into CNS-infiltrating effector cells in secondary lymphoid organs [195]. Therefore, all of these evidences strongly suggest that disease severity depends on the cooperation between CD4+ and CD8+ T cells.

On the other hand, CD4+ T cells expressing LatencyAssociated Peptides (LAP) suppress EAE depending on the TGF- $\beta$ [196]. But not only CD4+ T cells can express LAP. $\mathrm{CD} 8+\mathrm{LAP}+$ Treg comprise a novel subset that has a regulatory function and that reduces the disease severity of EAE by TGF- $\beta$ - and IFN- $\gamma$-dependent mechanisms [197].

In the same way that CD4+CD25+FoxP3+ does, CD8+CD28- Treg also regulate the balance between immunity and tolerance [174]. CD8+CD25+FoxP3+ T cells are IL-10 and TGF- $\beta$ producers and downregulate costimulatory molecule expression in dendritic cells through a STAT3-mediated pathway, inducing a less efficient antigen presentation and inducing 2,3-dioxygenase (IDO) through STAT3 and cytotoxic T lymphocyte antigen-4-dependent mechanisms [198]. Furthermore, CD8+ T cells, with immunosuppressive functions, are induced in MS patients treated with GA, and they appear to be HLA-E restricted [192]. These latter data demonstrate how CD8+ T cells can play a regulatory role in the evolution of MS.

\subsection{Adipose Tissue}

2.3.1. Adipose Tissue: Adipocytes. Although clinical evidence correlating obesity and MS is growing $[9,181]$, very little is known to date about the possible involvement of adipose tissue in MS pathogenesis as well as in cross talk among the tissues involved. Therefore, this constitutes a whole new field to be explored. It has been hypothesized that there is a link between metabolism and MS that involves proinflammatory mediators such as leptin, which promotes environmental conditions that in turn promote the loss of immune selftolerance [199]. Additionally, human adipocytes express the costimulatory receptor CD40, suggesting that these cells contribute to obesity-related inflammation. Also, $\mathrm{T}$ cells regulate adipokine production through soluble factors and contact with adipocytes, involving CD40 [200].

The apparently passive role played by adipocytes, in pathophysiological terms, has been gradually substituted with a metabolically active performance, relevant to many biochemical mechanisms that may contribute to a chronic low-grade inflammatory status, which increasingly imposes itself as a key feature of obesity [181]. As natural regulatory T cells (nTreg) do, adipocytes also could play an important role in the immunopathogenesis of MS and in the associated inflammation. In fact, very recently, cells that are able to differentiate into adipocytes, as mesenchymal stromal cells, are being utilized in transplantation as therapy to treat autoimmune diseases, in particular MS (see the last part of this review).

\section{Adipokines Involved in Cellular Cross Talk in MS}

Clinical and experimental data, together with epidemiological studies, have suggested that the pathogenesis of MS might involve factors that link the immune system with the metabolic status [199]. Therefore, a very exciting field in recent investigation comprises the role of adipokines in the pathogenesis of MS. Some studies have reported increased levels of leptin, resistin [32], and visfatin and decreased levels of adiponectin in patients with RRMS in comparison with healthy controls [33], a profile also observed among subjects with obesity [201-203] (Table 2).

\subsection{Adipokines}

3.1.1. Leptin. Leptin is an adipokine predominantly produced by adipose tissue and secreted into the circulation [204]. This adipokine is a regulator of body weight that promotes satiety and stimulates energy expenditure [205], and its levels correlate with the body adipose mass as well as with adipocyte size [206]. Leptin is upregulated by inflammatory mediators, such as TNF- $\alpha$, IL-1 [207], and IL-6 [208]. In addition to its metabolic effects, leptin is also a potent modulator of immune responses [209]. Thus, patients who are congenitally leptindeficient have a higher incidence of infection-related death due to dysfunctional immune response [210], with reduced numbers of circulating CD4+ T cells, impaired T cell proliferation, and cytokine release [211]. Leptin modulates immune response toward a proinflammatory profile and is found at the crossroads between inflammation and autoimmunity. Upsetting its balance may result in immunosuppressed condition, or, conversely, in a proinflammatory state, then facilitating the development of autoimmune diseases [2].

Leptin receptor (LepR) is expressed in CD4+, CD8+ [212, 213], Treg [214], and Natural Killer (NK) cells [215] and in monocytes/macrophages [212]. Because of the expression of their receptor, leptin induces differential effects in CD4+ T cells. Naïve T cells increased proliferation, whereas memory T cells were inhibited. Furthermore, leptin increases IFN- $\gamma$ production and inhibits IL-4 production in memory $\mathrm{T}$ cells [216].

In patients with MS, LepR expression has been found significantly higher in CD8+ T cells and monocytes from patients in relapse phase than that observed in patients in remission (or in healthy controls). Moreover, exogenous leptin treatment sustains STAT3 phosphorylation, but only in 


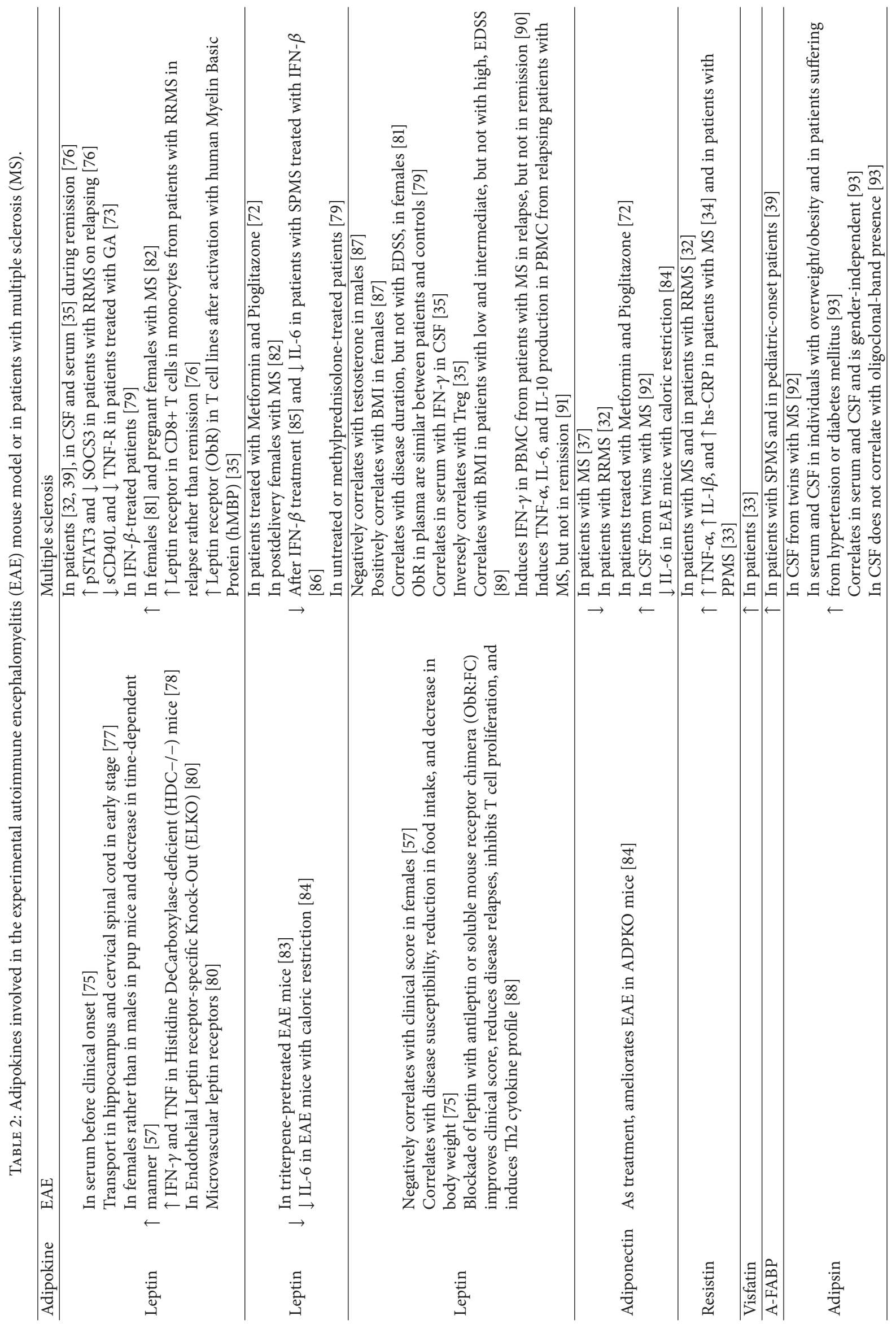




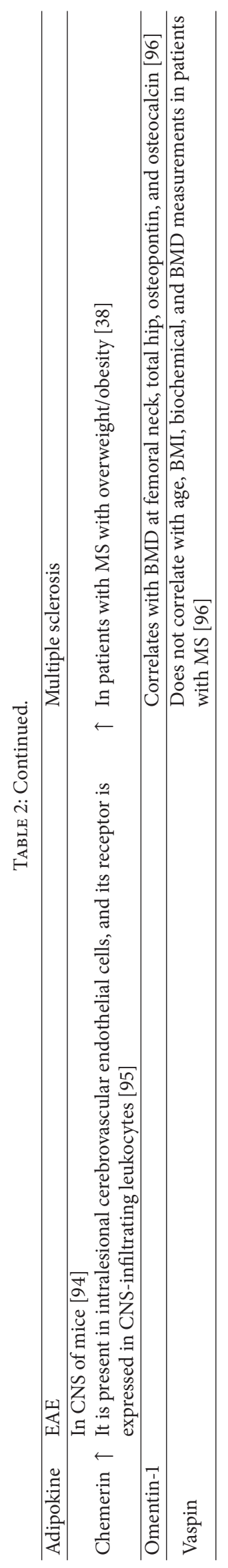


monocytes from relapsing patients [76], suggesting that LepR might play a role in the modulation of clinical relapses during MS. A gene microarray analysis of Thl lymphocytes from active MS lesions has shown elevated transcripts of many genes of the neuroimmune endocrine axis, including leptin [217]. Additionally, leptin serum levels are elevated in patients with MS before relapses and after treatment with IFN- $\beta$ [85]. These data suggest that leptin and its receptor induce Th1 cell and cytokine environment and favor the induction of inflammation in MS.

Moreover, in a recent work, Yu et al. demonstrated that Th17 cell frequency is reduced in leptin-deficient (ob/ob) mice and that the administration of exogenous leptin restores the Th17 cell count. Additionally, leptin induced Th17 response through ROR $\gamma$ t transcription in normal human $\mathrm{T}$ cells [218]. In the animal model of arthritis, leptin enhances Th17 cell response and exacerbates joint inflammation [219]. Thus, the findings suggest that leptin can induce an altered immune state and should contribute to neuroinflammation in MS through both Th1 and Th17 cell response.

Although there is evidence suggesting that leptin is associated with the development of CNS in mice [220, 221], it has been demonstrated in the animal model that $\mathrm{ob} / \mathrm{ob}$ mice are resistant to EAE induction and that leptindeficient (ob/ob) mice exhibit impaired cellular immune response, abnormal cytokine production, and impaired T cell proliferation [211]. Protection in ob/ob mice was associated with a progressive decline in the survival of autoreactive CD4+ T cells and reduced production of Th1 and Th17 cytokines. T cells demonstrated downregulation of $\mathrm{Bcl}-2$, a survival protein, reduction in P-ERK1/2, and cell-cycle arrest associated with reduced degradation of cell-cycle inhibitor p $27^{\mathrm{kip} 1}$. Additionally, there is impairment at the level of the nutrientenergy-sensing AKT-mTOR/S6 signaling pathway, which can be restored in vivo with leptin administration [222]. Taken together, the evidence allows the consideration of leptin and/or its receptor as important players in the pathogenesis of MS, as well as their consideration in therapeutic targets of the disease.

Matarese et al. found that leptin is increased in CSF and in the serum of patients with RRMS. These levels are related to IFN- $\gamma$ production in the CSF and, inversely, with the proportion of Treg [35]. In this respect, several studies showed that Treg accumulated in normal adipose tissue [223225].

Recently, the relationship between caloric restriction and survival in MS has been investigated. In an animal model, Piccio et al. established that caloric restriction and reduction of leptin serum levels can increase survival and lifespan through the reduction of inflammation, demyelination, and axonal injury [84]. At the same time, Longo and Fontana demonstrated that caloric restriction reduces inflammatory parameters and suggest that nutritional intervention improves the inflammatory response [226]. Caloric restriction has also been associated with an increase of the ghrelin, NeuroPeptide Y (NPY), which can moderate EAE [227]. All of the previous evidence indicates that leptin is able to participate as a link between metabolism and MS.
So, it is necessary to find out the role of neurohormonal response in the ingestion of food, which is orchestrated by the hypothalamic circuitry in patients with MS.

3.1.2. Adiponectin. Adiponectin (APN) is the most abundant circulating adipokine and is involved in metabolic diseases such as type 2 diabetes, metabolic syndrome, and related complications, especially cardiovascular diseases. Also, evidence indicates that APN is related to the severity of rheumatoid arthritis, systemic lupus erythematosus, and osteoarthritis [228]. Systemic and local levels of APN are elevated in patients with inflammatory and immune-mediated diseases [155, 168, 229].

APN exerts its effects through its receptors. AdipoR1 is expressed predominantly in skeletal muscle, AdipoR2 is found more abundantly in liver, and T-cadherin is mainly expressed in the cardiovascular system [230]. In this regard, APN exhibits anti-inflammatory activity on immune system cells [231]. Its functions include suppression of the proliferation of myelomonocytic precursor cells and the phagocytic activity of mature macrophages [232], regulation of monocyte-to-fibroblast transition [233], regulation of TNF$\alpha$ and IFN $-\gamma$ production in response antigen presentation [234], and the induction of IL-10 and IL-1 Receptor Antigen (IL-1RA) in monocytes, macrophages, and dendritic cells (DC) [2]. However, it has been reported that APN plays a dual role in immune system, indicating that APN possesses proinflammatory actions as a possible result of the presence of isoforms [2]. Jung et al. demonstrated that APN can promote DC activation, leading to Th1 and Th17 polarization [235].

Piccio et al. investigated the role of APN in adiponectin deficient (ADPKO) mice with EAE. These mice developed higher CNS inflammation, demyelination, and axonal injury. $\mathrm{T}$ cells from ADPKO mice produced higher levels of TNF$\alpha$, IFN- $\gamma$, IL-17, and IL- 6 and a decreased Treg number and function, demonstrating that the absence of APN contributes to elevating the disease severity. Furthermore, the use of APN as a treatment in these animals ameliorates EAE by the increase of the number of Treg [36]. These data indicate that APN could exert beneficial effects on the treatment of MS, but information on the role of APN with the animal model of MS is insufficient and more efforts must be made in this respect.

Regarding APN serum levels in patients with MS, Kraszula et al. observed that APN is decreased in patients with RRMS compared with healthy individuals. Also, the authors found higher levels of leptin, correlating with the number of Treg; however, APN was not correlated with Treg [32]. In line with these findings, Musabak et al. also found that the APN serum levels were lower than those of healthy controls, and these levels were higher in female than in male patients with MS. Then, it is possible that APN is genderdependent, because the same behavior is observed in healthy controls [37].

In contrast, Hietaharju et al. found higher CSF concentrations of APN and adipsin in twins with MS in remission compared with their asymptomatic twins, although these levels did not correlate with plasma levels. In this regard, the authors suggest that there is a possible intrathecal synthesis 
of adipokines or increased transport across the BBB following enhanced systemic production [92]. However, the sample size of this study is small; thus, there is a need for larger studies to clarify the significance of APN levels in patients with MS.

3.1.3. Resistin. Resistin is a mediator of insulin resistance and is also known as ADSF (ADipocyte-Secreted Factor) or FIZZ3 (found in inflammatory zone 3) [168, 236, 237]. This adipokine has been implicated in obesity, diabetes [238], atherosclerosis [239], coronary heart disease, and cardiovascular disease [240]. Additionally, there is evidence that serum resistin levels are increased in patients with rheumatoid arthritis (RA) [241].

These adipokines are produced by adipocytes [242], intestinal epithelium, adrenal gland, and skeletal muscle [243]. It has been reported that resistin can be expressed in CNS by the pituitary gland and that its expression is age- and gender-dependent in mice [244]. Also, resistin can influence sympathetic nerve activity in CNS [245].

A few studies had attempted to discover the relationship between resistin and MS pathogenesis in patients with the disease [32-34]. In an endeavor to determine the possible association, Emamgholipour et al. observed an elevation of resistin, leptin, and visfatin levels, as well as a decrease in the FoxP3 mRNA expression of T cells. Additionally, the authors found that these adipokines are positively correlated with some inflammation mediators in healthy controls, suggesting that adipokines may play a role as inducers of proinflammatory mediators (TNF- $\alpha$, IL-1 $\beta$, and hs-CRP) [33]. HosseinNezhad et al. also found higher serum levels of resistin in patients with MS compared with the control group [34], which adds evidence to support the role of resistin in MS, although more studies are needed.

3.1.4. Visfatin. Visfatin was originally known as PBEF (Pre$\mathrm{B}$ cell colony-Enhancing Factor). Leukocytes, adipose tissue macrophages, hepatocytes, or skeletal muscle participates in visfatin production [246]. Visfatin is related to glucose metabolism because it can bind to and activate the insulin receptor [247].

In the area of immune activities, visfatin induces the production of IL- 6 , TNF- $\alpha$, and IL- $1 \beta$ in monocytes. Moreover, visfatin increases the surface expression of costimulatory molecules CD54, CD40, and CD80 [248]. In RA, visfatin is described as a proinflammatory and destructive mediator of joint inflammation in RA [249]. Emamgholipour et al. found a positive correlation of visfatin with TNF- $\alpha$, IL- $1 \beta$, and hsCRP in patients with MS [33]. Almost nothing is known about the relationship between visfatin and MS.

3.1.5. Adipocyte-Fatty Acid-Binding Protein. Serum Adipocyte-Fatty Acid-Binding Protein (A-FABP) is produced by adipose tissue, monocytes, and macrophages, and its expression is enhanced by Toll-Like Receptor-2 (TLR-2) stimulation [250]. Higher levels of A-FABP have been associated with increased triglycerides, elevated fasting serum glucose, and hs-CRP in coronary artery disease [251]. Regarding MS, AFABP levels are highest in Secondary Progressive MS (SPMS), suggesting a possible role in the pathogenesis of this disease subtype. Also, A-FABP levels are increased in patients with Pediatric-Onset MS (POMS) and may play a role in the early stages of disease [39]. Therefore, more studies are necessary on this adipokine and its relationship with MS pathogenesis in humans and the animal model to clarify the mechanisms in which A-FABP is involved.

3.1.6. Adipsin. Adipsin was described as a molecular marker of obesity in rodents [252]. The function of adipsin in relation to energy homeostasis and systemic metabolism remains unknown [253]. In patients with a specific neurological diagnosis without prior selection, serum adipsin levels are correlated with CSF levels. Also, serum and CSF levels are correlated with age and are higher in patients with diabetes mellitus or hypertension. Adipsin CSF levels are correlated with inflammation mediators, but not with the presence of oligoclonal bands [93]. In a study of twins with MS, Hietaharju et al. found higher CSF concentrations of APN and adipsin in twins with MS in remission compared with their asymptomatic twins and no correlation with its plasma levels [92]. Recently, a study conducted by Natarajan et al. has provided novel insights into the impact of adipokines on MS and suggests that adipsin exerts predictive potential as a biomarker of neurodegeneration [254]. However, very little is known about the role of adipsin in MS pathogenesis; therefore, more studies are needed.

3.1.7. Chemerin. Chemerin is an adipokine secreted by adipocytes and is associated with obesity, the metabolic syndrome, and insulin resistance [255]. Chemerin has been identified as a chemoattractant for Antigen Presenting Cells (APC), including DC and macrophages; in addition its receptor ChemR23 induces the release of calcium, inhibition of cAMP accumulation, and phosphorylation of p42-p44 MAP kinases [256]. In addition, chemerin is a proteolytically regulated leukocyte chemoattractant when it binds to CheMoKine-Like Receptor-1 (CMKLR-1) [94].

This adipokine is expressed in vascular Endothelial Cells in the meninges and in white-matter lesions of MS, whereas its receptor is expressed in infiltrating leukocytes, including plasmacytoid DC. These data suggest that chemerin is directly involved in the migration of peripheral cells into the CNS and that they contribute to the inflammatory process [95]. CMKLR-1 Knock-Out (KO) mice exhibit reduced symptoms of EAE [94]. It has been demonstrated that targeting with alpha-NETA ( $\alpha$-NETA), an antagonist of CMKLR1, inhibits CNS-infiltrating cells and modulates inflammation in EAE mice. However, $\alpha$-NETA does not modify $\mathrm{T}$ cell proliferation [257]. In a recent study, it was found that chemerin plasma levels are higher in patients with MS with overweight or obesity compared with patients with MS and without obesity and controls [38]. These results suggest that obesity in patients with MS increases chemerin levels and causes an increase in CNS-infiltrating cells that may, in turn, contribute to disease severity.

3.1.8. Omentin. Omentin is produced mainly by Visceral Adipose Tissue and its expression is reduced in obesity, 
insulin resistance, and type 2 diabetes. This adipokine has anti-inflammatory, antiatherogenic, anticardiovascular, and antidiabetic effects [258]. In patients with MS, omentin1 serum levels are correlated with Bone Mineral Density (BMD) at femoral neck, total hip, osteopontin, and osteocalcin [96]. It has been reported that omentin-1 is involved with insulin activity, induces Akt phosphorylation [259], and is inversely correlated with obesity [260]. These evidences provide little knowledge; thus, more studies on these adipokines are needed to establish whether or not omentin participated in the pathogenesis of MS.

3.1.9. Vaspin. Vaspin is an adipokine that is predominantly secreted by Visceral Adipose Tissue and its serum levels are increased and associated with obesity and impaired insulin sensitivity. To the contrary, its correlation is abrogated in type 2 diabetes and its levels are higher in females as compared with males [261]. Vaspin has been poorly studied in patients with MS. In this regard, Assadi et al. did not find any correlation between vaspin and age, BMI, biochemical, and BMD measurements in patients with MS [96].

In summary, dysregulated adipokines can be involved in the pathophysiology of MS, increasing the risk of the disease development after obesity, during adolescence or the earlyadult stage, as well as influencing elements that affect disease evolution and treatment response for obese adults with MS (Figure 1). Undoubtedly, there remains such research to be conducted with regard to these aspects.

\section{Transplantation of Adipose Tissue-Mesenchymal Stem Cells as Therapy for MS}

Mesenchymal Stem Cells (MSC) are a pleiotropic population of precursor cells that are self-renewing and capable of differentiating into canonical cells of the mesenchyme, including adipocytes, chondrocytes, and osteocytes [262]. Due to their immunomodulatory and neuroprotective effects, Adipose Tissue-Mesenchymal Stem Cells (AT-MSC) may be proper candidates for stem cell-based MS therapy. The intraperitoneal (i.p.) route exerts a more pronounced effect on maintaining splenic CD4+CD25+FOXP3+ T cell population and increasing IL- 4 secretion. In addition, i.p. injection of cells resulted in lower IFN- $\gamma$ secretion and reduced cell infiltration in brain more effectively as compared with the intravascular (i.v.) route [263].

In mice with established EAE, in vivo infusion of wildtype Adipose Stromal/Stem Cells (ASC) significantly ameliorated the disease course, autoimmune-mediated demyelination, and cell infiltration through regulation of the inflammatory responses. However, mice treated with autologous ASC exhibited no therapeutic improvement in terms of disease progression [264].

The preclinical efficacy of AT-MSC obtained from the SJL/JCrl mouse strain (SJL-AdMSC) has been assessed by autologous transplantation in RR-EAE-induced SJL mice (a well-established mouse model for the study of RRMS) by ameliorating the RR-EAE course, suggesting that these could modulate disease progression [265].
The therapeutic efficacy of ASC isolated from lean subjects (BMI < 25, lnASC) and subjects with obesity (BMI $>30$ in ObASC) were determined in murine EAE. Compared with EAE disease-modifying effects of InASC, ObASC consistently failed to alleviate clinical symptoms or to inhibit inflammation in the CNS. When activated, ObASC expressed higher mRNA levels of several proinflammatory cytokines compared with InASC. Additionally, Conditioned Media (CM) collected from ObASC markedly enhanced T cell proliferation and differentiation, whereas CM from lnASC did not. These results indicate that obesity reduces, or eliminates, the anti-inflammatory effects of human ASC; therefore, they may not be a suitable cell source for the treatment of autoimmune diseases. The data suggest that donor demographics may be particularly important when identifying suitable stem cells for treatment [266].

The majority of Mesenchymal Stem Cells (MSC) clinical trials are currently in phase 2 of development, during which safety and tolerability of treatment continue to be evaluated (Table 3). These works include patients with median or high Expanded Disability Status Score (EDSS) and who are mainly in the SPMS stage. Sample size is reduced and the protocol of administration is variable, both in number of cells transplanted and in the administration pathway (mainly intravenously or intrathecally). It appears to be that, in the majority of cases, there is a decrease in the EDSS index after transplantation; however, it is necessary to follow up patients for a longer time period ( $>6$ months) and to be more accurate with respect to the possible improvement achieved. The results are also highly variable, as well as the adverse events presented (see summary, Table 3). Consequently, although AT-MSC transplantation can be regarded as a potential source of treatment for MS, several studies now at clinical stages need to see whether these show a real benefit in practice, particularly in MS progressive stages (PPMS and SPMS). These works will contribute to the design of future trials conducted to establish whether MSC transplantation comprises an effective therapy for patients with MS.

In conclusion, since the discovery of the remarkable properties of adipose tissue the possible link between MS and obesity has been rendered even more interesting. Several evidences on the possible link between obesity and the pathogenesis of MS were discussed. Although it is wellknown that CNS and immune system cells are involved in the pathogenesis of MS, adipokines comprise the possible cross talk between them (Figure 2). Therefore, it will be also relevant to explore the role of neuropeptides, like NPY, leptin, ghrelin, and other proteins, in relation to feeding behavior, whose mechanisms are regulated by orexigenic and anorexigenic hypothalamic neurons, because an adequate regulation of this neural circuitry will be related to an improvement in the inflammatory response and survival in MS. Finally, it seems to be more clear that once MS is initiated, obesity can contribute to increasing disease severity by negatively influencing disease progress and treatment response, but, also, obesity in early life (mainly during adolescence) is highly relevant as a susceptibility factor and causally related increased risk for late MS development. 


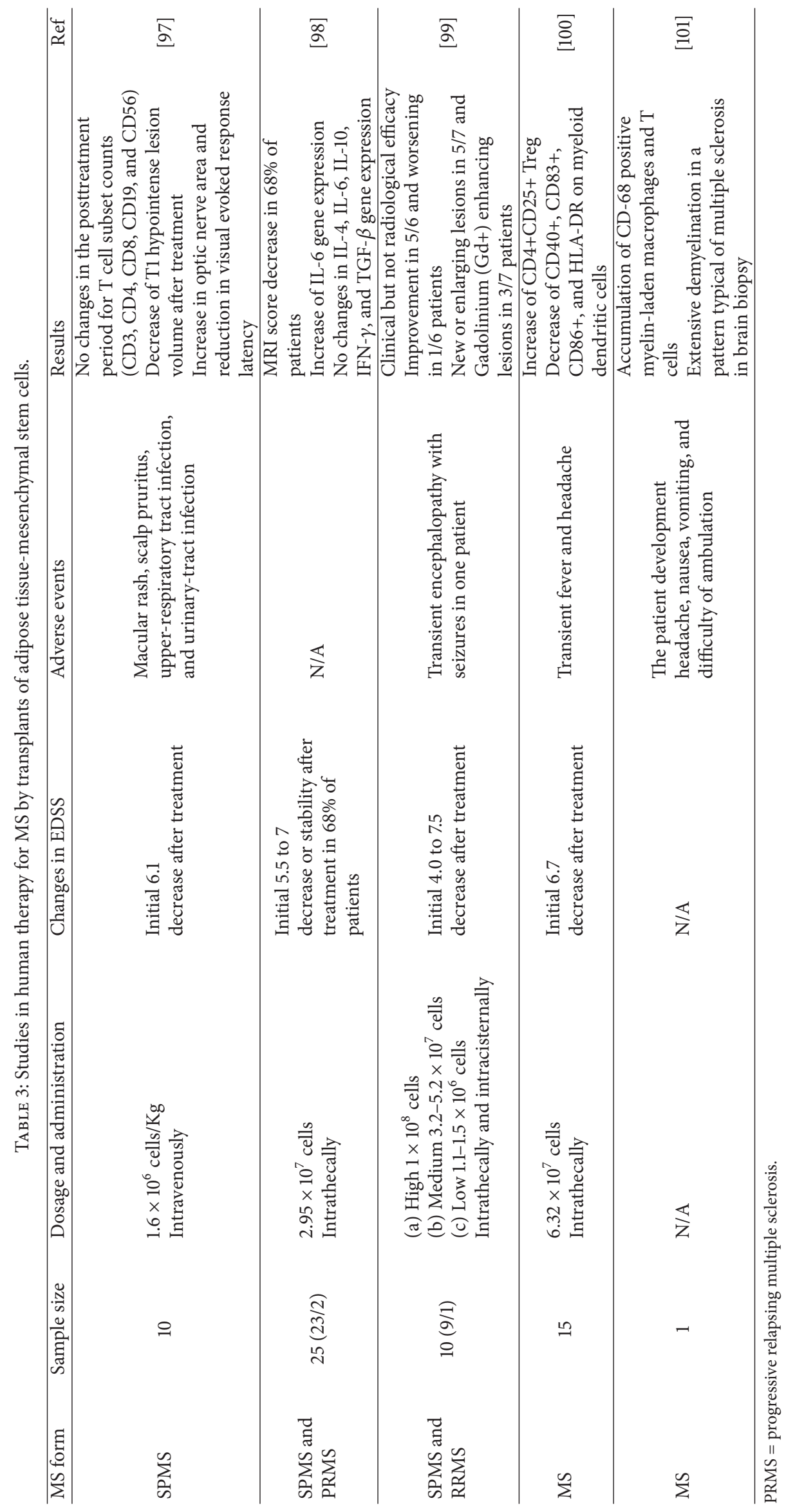




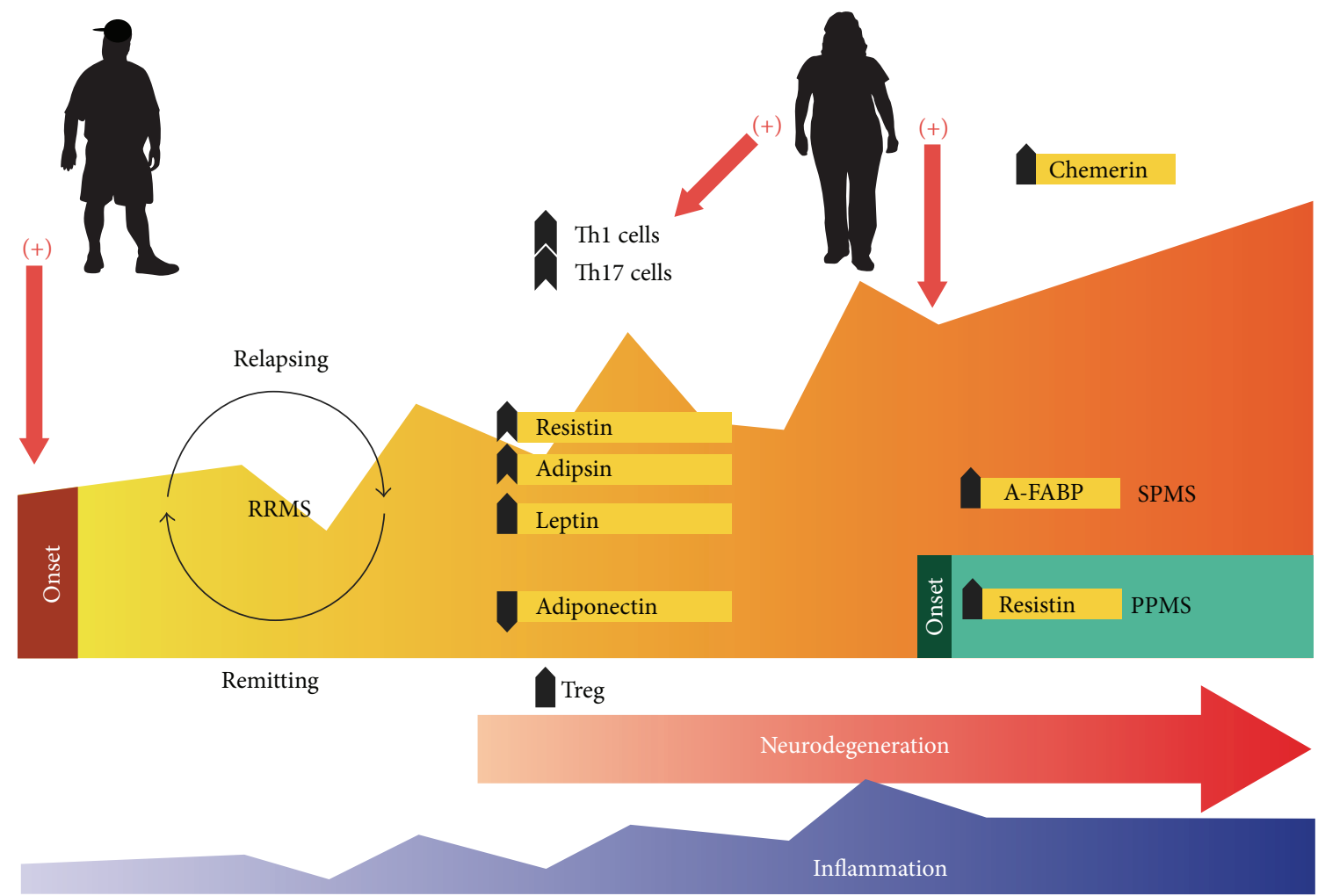

FIGURE 1: An integrative view of the possible involvement of some adipokines present in patients with multiple sclerosis (MS) at different disease stages. Obesity during adolescence constitutes a relevant risk factor for the later development of MS. Adult obesity negatively affects evolution of the disease and response to treatment in patients with MS. During relapsing-remitting stages, a decrease in adiponectin has been reported as well as, concomitantly, an increase in resistin, adipsin, and leptin concentrations (in serum or CSF or both). Additionally, A-FABP is increased in patients with SPMS, and resistin is also increased in patients with PPMS. Given that inflammation occurs at a variable intensity from the onset of the disease and that neurodegeneration process starts after disease initiation, in this context the adipokines produced by lipid tissue constitute an additional element in the neuroimmunomodulation complex of organisms with MS (see text for further explanation); thus the adipokines produced constitute an additional element in the neuroimmunomodulation complex of organisms with MS (see text for further explanation). RRMS, Remittent Recurrent Multiple Sclerosis. SPMS, Secondary Progressive Multiple Sclerosis. PPMS, Primary Progressive Multiple Sclerosis. CSF, CerebroSpinal Fluid. Resistin (serum) [32-34]. Adipsin (in CSF) [35]. Leptin (serum and CSF) [35]. Adiponectin (in serum) [32, 36, 37]. Chemerin (serum) [38]. A-FABP, Adipocyte-Fatty Acid-Binding Protein (in serum) [39].

\section{Abbreviations}

APN: Adiponectin

BBB: Blood Brain Barrier

CNS: Central Nervous System

CSF: CerebroSpinal Fluid

EDSS: Disability Status Scale

EC: $\quad$ Endothelial Cells

EAE: Experimental Autoimmune

Encephalomyelitis

GA: Glatiramer Acetate

GS: Glutamine Synthetase

GDH: Glutamate DeHydrogenase

IGF-1: Insulin-Like Growth Factor-1

ICAM-1: IntraCellular Adhesion Molecule-1

MOG: Myelin Oligodendrocyte

Glycoprotein

MS: $\quad$ Multiple Sclerosis

OPC: Oligodendrocyte Precursor Cells

PERK: Pancreatic Endoplasmic Reticulum Kinase
POMS: Pediatric-Onset MS

PBMC: Peripheral Blood Mononuclear Cells

PPAR- $\gamma$ : Peroxisome Proliferator-Activated

Receptor gamma

PD-L1: Programmed Death-Ligand-1

PD1: $\quad$ Programmed Death-1

SPMS: Secondary Progressive MS

A-FABP: Adipocyte-Fatty Acid-Binding Protein

SAT: $\quad$ Subcutaneous Adipose Tissue

VAT: $\quad$ Visceral Adipose Tissue.

\section{Additional Points}

Apologies are due to authors whose works have not been reviewed and to those whose papers have not received the emphasis that they merit. The authors also apologize to authors whose work has not been appropriately cited due to space limitations and/or to limitations of the present paper's authors' knowledge. 


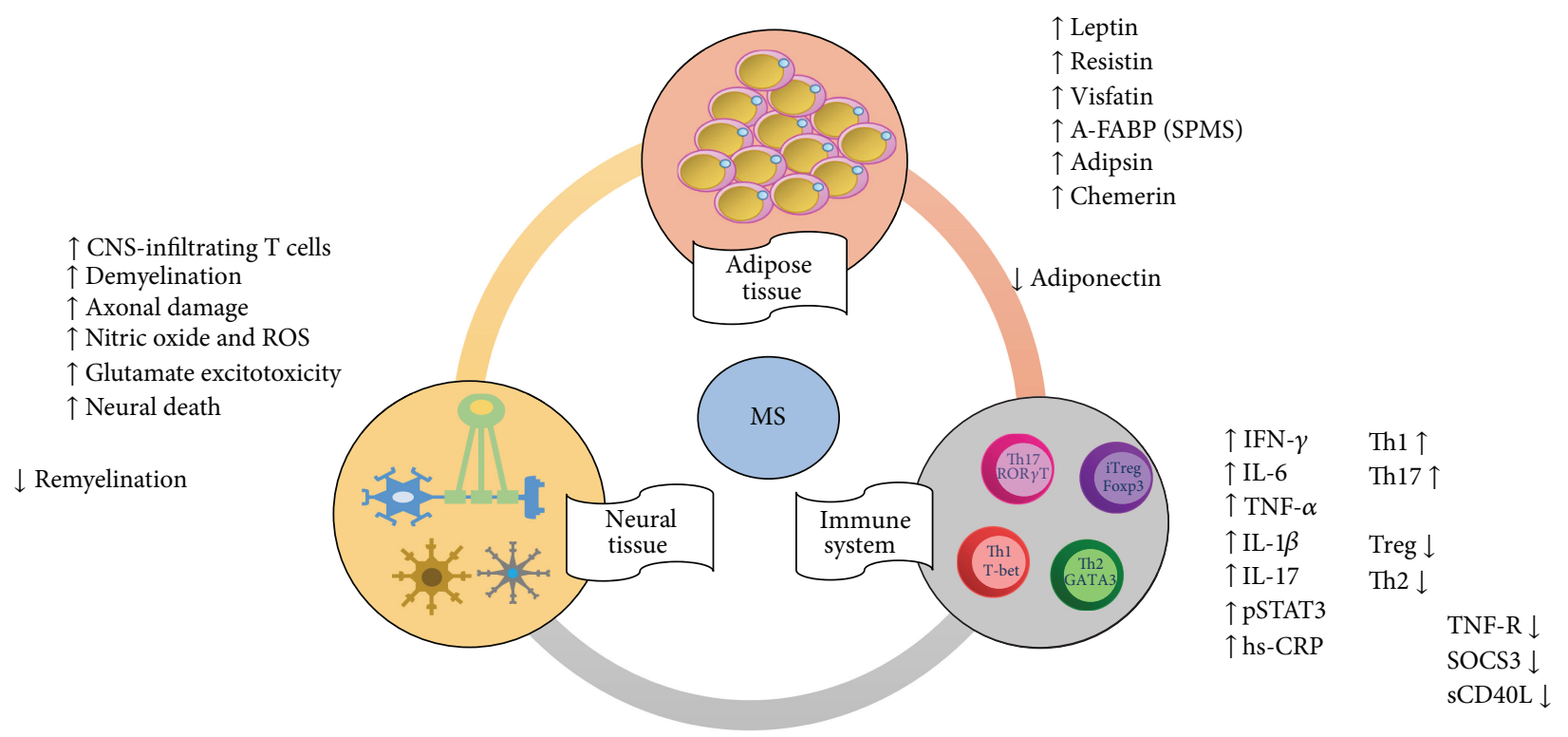

FIGURE 2: Cross talk among immune, neural, and adipose tissues. Adipocytes release leptin, resistin, and visfatin, which induce a low-grade inflammatory state in patients with multiple sclerosis (MS) with obesity. T cells migrate into the Central Nervous System (CNS), with Th1/Th17 cell release of proinflammatory cytokines, which promote the inflammatory status, and Th2/Treg release of anti-inflammatory cytokines, which contributes to modulating the severity of multiple sclerosis (MS). Neurons and oligodendrocytes are those mainly affected in MS. Axons are demyelinated by cell- and molecular-mediated mechanisms. Antigen presentation between microglia and CNS-infiltrating T cells induces a proinflammatory positive feedback loop. Astrocytes costimulate CNS-infiltrating T cells through CD24 expression.

\section{Competing Interests}

The authors declare that there is no conflict of interests regarding the publication of this article.

\section{Authors' Contributions}

José de Jesús Guerrero-García, Lucrecia Carrera-Quintanar, Rocío Ivette López-Roa, Ana Laura Márquez-Aguirre, Argelia Esperanza Rojas-Mayorquín, and Daniel OrtuñoSahagún drafted the paper. All authors reviewed the paper and approved the final version.

\section{Acknowledgments}

The study was partially supported by Universidad de Guadalajara Grant 227303 PRO-SNI 2015 to Daniel OrtuñoSahagún; CONACyT-México Grants CB-2012-180268 to Argelia Esperanza Rojas-Mayorquín, CB-2015-256736 to Rocío Ivette López-Roa, and PROMEP/103.5/12/8143 to Argelia Esperanza Rojas-Mayorquín. Fellowship support was provided by CONACyT-México Postdoctoral 170901 to Lucrecia Carrera-Quintanar. The authors wish to thank Juan Bernardo Magallanes Ulloa who assisted in design of Figure 1.

\section{References}

[1] L. Moroni, I. Bianchi, and A. Lleo, "Geoepidemiology, gender and autoimmune disease," Autoimmunity Reviews, vol. 11, no. 6-7, pp. A386-A392, 2012.
[2] M. Versini, P.-Y. Jeandel, E. Rosenthal, and Y. Shoenfeld, "Obesity in autoimmune diseases: not a passive bystander," Autoimmunity Reviews, vol. 13, no. 9, pp. 981-1000, 2014.

[3] WHO, "Overweight/obesity: overweight by country. Global Health Observatory Data Repository 2008-2013," 2016, http:// www.who.int/gho/ncd/risk_factors/obesity_text/en/.

[4] E. Gremese, B. Tolusso, M. R. Gigante, and G. Ferraccioli, "Obesity as a risk and severity factor in rheumatic diseases (autoimmune chronic inflammatory diseases)," Frontiers in Immunology, vol. 5, article 576, 2014.

[5] S. Overs, C. M. Hughes, J. K. Haselkorn, and A. P. Turner, "Modifiable comorbidities and disability in multiple sclerosis," Current Neurology and Neuroscience Reports, vol. 12, no. 5, pp. 610-617, 2012.

[6] R. Milo and A. Miller, "Revised diagnostic criteria of multiple sclerosis," Autoimmunity Reviews, vol. 13, no. 4-5, pp. 518-524, 2014.

[7] S. Schwarz and H. Leweling, "Multiple sclerosis and nutrition," Multiple Sclerosis, vol. 11, no. 1, pp. 24-32, 2005.

[8] R. L. Swank and B. B. Dugan, "Effect of low saturated fat diet in early and late cases of multiple sclerosis," The Lancet, vol. 336, no. 8706, pp. 37-39, 1990.

[9] C. H. Marck, S. L. Neate, K. L. Taylor, T. J. Weiland, and G. A. Jelinek, "Prevalence of comorbidities, overweight and obesity in an international sample of people with multiple sclerosis and associations with modifiable lifestyle factors," PLoS ONE, vol. 11, no. 2, Article ID e0148573, 2016.

[10] A. Hedström, L. Alfredsson, and T. Olsson, "Environmental factors and their interactions with risk genotypes in MS susceptibility," Current Opinion in Neurology, vol. 29, no. 3, pp. 293298, 2016. 
[11] H. Beltrán-Sánchez, M. O. Harhay, M. M. Harhay, and S. McElligott, "Prevalence and trends of metabolic syndrome in the adult U.S. population, 1999-2010," Journal of the American College of Cardiology, vol. 62, no. 8, pp. 697-703, 2013.

[12] J. N. Slawta, A. R. Wilcox, J. A. McCubbin, D. J. Nalle, S. D. Fox, and G. Anderson, "Health behaviors, body composition, and coronary heart disease risk in women with multiple sclerosis," Archives of Physical Medicine and Rehabilitation, vol. 84, no. 12, pp. 1823-1830, 2003.

[13] M. Markianos, M.-E. Evangelopoulos, G. Koutsis, P. Davaki, and C. Sfagos, "Body mass index in multiple sclerosis: associations with CSF neurotransmitter metabolite levels," ISRN Neurology, vol. 2013, Article ID 981070, 6 pages, 2013.

[14] S. R. Khurana, A. M. Bamer, A. P. Turner et al., "The prevalence of overweight and obesity in veterans with multiple sclerosis," American Journal of Physical Medicine and Rehabilitation, vol. 88, no. 2, pp. 83-91, 2009.

[15] A. K. Hedström, T. Olsson, and L. Alfredsson, "High body mass index before age 20 is associated with increased risk for multiple sclerosis in both men and women," Multiple Sclerosis Journal, vol. 18, no. 9, pp. 1334-1336, 2012.

[16] A. Langer-Gould, S. M. Brara, B. E. Beaber, and C. Koebnick, "Childhood obesity and risk of pediatric multiple sclerosis and clinically isolated syndrome," Neurology, vol. 80, no. 6, pp. 548552, 2013.

[17] K. L. Munger, J. Bentzen, B. Laursen et al., "Childhood body mass index and multiple sclerosis risk: A Long-Term Cohort Study," Multiple Sclerosis Journal, vol. 19, no. 10, pp. 1323-1329, 2013.

[18] K. L. Munger, T. Chitnis, and A. Ascherio, "Body size and risk of MS in two cohorts of US women," Neurology, vol. 73, no. 19, pp. 1543-1550, 2009.

[19] K. Wesnes, T. Riise, I. Casetta et al., "Body size and the risk of multiple sclerosis in Norway and Italy: the EnvIMS study," Multiple Sclerosis Journal, vol. 21, no. 4, pp. 388-395, 2015.

[20] R. A. Marrie, R. I. Horwitz, G. Cutter, T. Tyry, and T. Vollmer, "Association between comorbidity and clinical characteristics of MS," Acta Neurologica Scandinavica, vol. 124, no. 2, pp. 135-141, 2011.

[21] J. Cambil-Martín, N. Galiano-Castillo, E. Muñoz-Hellín et al., "Influence of body mass index on psychological and functional outcomes in patients with multiple sclerosis: a cross-sectional study," Nutritional Neuroscience, vol. 19, no. 2, pp. 79-85, 2016.

[22] K. L. Taylor, E. J. Hadgkiss, G. A. Jelinek et al., "Lifestyle factors, demographics and medications associated with depression risk in an international sample of people with multiple sclerosis," BMC Psychiatry, vol. 14, article 327, 2014.

[23] I. Wens, U. Dalgas, E. Stenager, and B. O. Eijnde, "Risk factors related to cardiovascular diseases and the metabolic syndrome in multiple sclerosis-a systematic review," Multiple Sclerosis Journal, vol. 19, no. 12, pp. 1556-1564, 2013.

[24] S. R. Oliveira, A. N. Colado Simão, A. P. Kallaur et al., "Disability in patients with multiple sclerosis: influence of insulin resistance, adiposity, and oxidative stress," Nutrition, vol. 30, no. 3, pp. 268-273, 2014.

[25] R. A. Marrie, R. Rudick, R. Horwitz et al., "Vascular comorbidity is associated with more rapid disability progression in multiple sclerosis," Neurology, vol. 74, no. 13, pp. 1041-1047, 2010.

[26] B. Weinstock-Guttman, R. Zivadinov, N. Mahfooz et al., "Serum lipid profiles are associated with disability and MRI outcomes in multiple sclerosis," Journal of Neuroinflammation, vol. 8, article 127, 2011.
[27] S. R. Oliveira, A. P. Kallaur, A. N. C. Simão et al., "Oxidative stress in multiple sclerosis patients in clinical remission: association with the expanded disability status scale," Journal of the Neurological Sciences, vol. 321, no. 1-2, pp. 49-53, 2012.

[28] A. K. Hedstrom, T. Olsson, and L. Alfredsson, "Body mass index during adolescence, rather than childhood, is critical in determining MS risk," Multiple Sclerosis Journal, vol. 22, no. 7, pp. 878-883, 2016.

[29] L. E. Mokry, S. Ross, N. J. Timpson et al., "Obesity and multiple sclerosis: a mendelian randomization study," PLoS Medicine, vol. 13, no. 6, Article ID e1002053, 2016.

[30] S. Nishimura, I. Manabe, S. Takaki et al., "Adipose natural regulatory B cells negatively control adipose tissue inflammation," Cell Metabolism, vol. 18, no. 5, pp. 759-766, 2013.

[31] S. E. Shoelson, J. Lee, and A. B. Goldfine, "Inflammation and insulin resistance," The Journal of Clinical Investigation, vol. 116, no. 7, pp. 1793-1801, 2006.

[32] Ł. Kraszula, A. Jasińska, M.-O. Eusebio, P. Kuna, A. Głabiński, and M. Pietruczuk, "Evaluation of the relationship between leptin, resistin, adiponectin and natural regulatory $\mathrm{T}$ cells in relapsing-remitting multiple sclerosis," Neurologia i Neurochirurgia Polska, vol. 46, no. 1, pp. 22-28, 2012.

[33] S. Emamgholipour, S. M. Eshaghi, A. Hossein-nezhad, K. Mirzaei, Z. Maghbooli, and M. A. Sahraian, "Adipocytokine profile, cytokine levels and Foxp3 expression in multiple sclerosis: a possible link to susceptibility and clinical course of disease," PLoS ONE, vol. 8, no. 10, article e76555, 2013.

[34] A. Hossein-Nezhad, F. N. Varzaneh, K. Mirzaei, S. Emamgholipour, F. N. Varzaneh, and M. A. Sahraian, "A polymorphism in the resistin gene promoter and the risk of multiple sclerosis," Minerva Medica, vol. 104, no. 4, pp. 431-438, 2013.

[35] G. Matarese, P. B. Carrieri, A. La Cava et al., "Leptin increase in multiple sclerosis associates with reduced number of $\mathrm{CD} 4{ }^{+} \mathrm{CD} 25^{+}$regulatory T cells," Proceedings of the National Academy of Sciences of the United States of America, vol. 102, no. 14, pp. 5150-5155, 2005.

[36] L. Piccio, C. Cantoni, J. G. Henderson et al., "Lack of adiponectin leads to increased lymphocyte activation and increased disease severity in a mouse model of multiple sclerosis," European Journal of Immunology, vol. 43, no. 8, pp. 20892100, 2013.

[37] U. Musabak, S. Demirkaya, G. Genç, R. S. Ilikci, and Z. Odabasi, "Serum adiponectin, TNF- $\alpha$, IL-12p70, and IL-13 levels in multiple sclerosis and the effects of different therapy regimens," NeuroImmunoModulation, vol. 18, no. 1, pp. 57-66, 2011.

[38] J. Tomalka-Kochanowska, B. Baranowska, E. Wolinska-Witort et al., "Plasma chemerin levels in patients with multiple sclerosis," Neuroendocrinology Letters, vol. 35, no. 3, pp. 218-223, 2014.

[39] S. Messina, D. Vargas-Lowy, A. Musallam et al., "Increased leptin and A-FABP levels in relapsing and progressive forms of MS," BMC Neurology, vol. 13, article 172, 2013.

[40] A. Shemer, D. Erny, S. Jung, and M. Prinz, "Microglia plasticity during health and disease: an immunological perspective," Trends in Immunology, vol. 36, no. 10, pp. 614-624, 2015.

[41] J. Hu, H. He, Z. Yang et al., "Programmed death ligand1 on microglia regulates Th1 differentiation via nitric oxide in experimental autoimmune encephalomyelitis," Neuroscience Bulletin, vol. 32, no. 1, pp. 70-82, 2016.

[42] M. A. Lynch, "The multifaceted profile of activated microglia," Molecular Neurobiology, vol. 40, no. 2, pp. 139-156, 2009. 
[43] X. Fan, H. Zhang, Y. Cheng, X. Jiang, J. Zhu, and T. Jin, "Double roles of macrophages in human neuroimmune diseases and their animal models," Mediators of Inflammation, vol. 2016, Article ID 8489251, 13 pages, 2016.

[44] J. W. Peterson, L. Bö, S. Mörk, A. Chang, R. M. Ransohoff, and B. D. Trapp, "VCAM-1-positive microglia target oligodendrocytes at the border of multiple sclerosis lesions," Journal of Neuropathology and Experimental Neurology, vol. 61, no. 6, pp. 539-546, 2002.

[45] R. Huizinga, B. J. van der Star, M. Kipp et al., "Phagocytosis of neuronal debris by microglia is associated with neuronal damage in multiple sclerosis," Glia, vol. 60, no. 3, pp. 422-431, 2012.

[46] L. A. N. Peferoen, D. Y. S. Vogel, K. Ummenthum et al., "Activation status of human microglia is dependent on lesion formation stage and remyelination in multiple sclerosis," Journal of Neuropathology and Experimental Neurology, vol. 74, no. 1, pp. 48-63, 2015.

[47] Á. C. Murphy, S. J. Lalor, M. A. Lynch, and K. H. G. Mills, "Infiltration of Th1 and Th17 cells and activation of microglia in the CNS during the course of experimental autoimmune encephalomyelitis," Brain, Behavior, and Immunity, vol. 24, no. 4, pp. 641-651, 2010.

[48] S. Chabot, F. P. Yong, D. M. Le, L. M. Metz, T. Myles, and V. W. Yong, "Cytokine production in T lymphocyte-microglia interaction is attenuated by glatiramer acetate: a mechanism for therapeutic efficacy in multiple sclerosis," Multiple Sclerosis, vol. 8, no. 4, pp. 299-306, 2002.

[49] M. Michels, L. G. Danieslki, A. Vieira et al., "CD40-CD40 ligand pathway is a major component of acute neuroinflammation and contributes to long-term cognitive dysfunction after sepsis," Molecular Medicine, vol. 21, pp. 219-226, 2015.

[50] G.-H. Schernthaner, H.-P. Kopp, K. Krzyzanowska, S. Kriwanek, R. Koppensteiner, and G. Schernthaner, "Soluble CD40L in patients with morbid obesity: significant reduction after bariatric surgery," European Journal of Clinical Investigation, vol. 36, no. 6, pp. 395-401, 2006.

[51] A. Chatzigeorgiou, M. Lyberi, G. Chatzilymperis, A. Nezos, and E. Kamper, "CD40/CD40L signaling and its implication in health and disease," BioFactors, vol. 35, no. 6, pp. 474-483, 2009.

[52] T. G. D’Aversa, K. M. Weidenheim, and J. W. Berman, “CD40CD40L interactions induce chemokine expression by human microglia: implications for human immunodeficiency virus encephalitis and multiple sclerosis," American Journal of Pathology, vol. 160, no. 2, pp. 559-567, 2002.

[53] J. Shijie, H. Takeuchi, I. Yawata et al., "Blockade of glutamate release from microglia attenuates experimental autoimmune encephalomyelitis in mice," The Tohoku Journal of Experimental Medicine, vol. 217, no. 2, pp. 87-92, 2009.

[54] P. Werner, D. Pitt, and C. S. Raine, "Multiple sclerosis: altered glutamate homeostasis in lesions correlates with oligodendrocyre and axonal damage," Annals of Neurology, vol. 50, no. 2, pp. 169-180, 2001.

[55] A. Gentile, F. De Vito, D. Fresegna et al., "Exploring the role of microglia in mood disorders associated with experimental multiple sclerosis," Frontiers in Cellular Neuroscience, vol. 9, article 243, 2015.

[56] O. Butovsky, Y. Ziv, A. Schwartz et al., "Microglia activated by IL- 4 or IFN- $\gamma$ differentially induce neurogenesis and oligodendrogenesis from adult stem/progenitor cells," Molecular and Cellular Neuroscience, vol. 31, no. 1, pp. 149-160, 2006.
[57] S. Columba-Cabezas, B. Serafini, E. Ambrosini et al., "Induction of macrophage-derived chemokine/CCL22 expression in experimental autoimmune encephalomyelitis and cultured microglia: implications for disease regulation," Journal of Neuroimmunology, vol. 130, no. 1-2, pp. 10-21, 2002.

[58] T. Magnus, B. Schreiner, T. Korn et al., "Microglial expression of the B7 family member B7 homolog 1 confers strong immune inhibition: implications for immune responses and autoimmunity in the CNS," The Journal of Neuroscience, vol. 25, no. 10, pp. 2537-2546, 2005.

[59] Y.-H. Jin, W. Hou, H. S. Kang, C.-S. Koh, and B. S. Kim, "The role of interleukin- 6 in the expression of PD-1 and PDL-1 on central nervous system cells following infection with Theiler's murine encephalomyelitis virus," Journal of Virology, vol. 87, no. 21, pp. 11538-11551, 2013.

[60] A. Rogue, C. Spire, M. Brun, N. Claude, and A. Guillouzo, “Gene expression changes induced by PPAR gamma agonists in animal and human liver," PPAR Research, vol. 2010, Article ID 325183, 16 pages, 2010.

[61] C. B. Duvanel, P. Honegger, H. Pershadsingh, D. Feinstein, and J.-M. Matthieu, "Inhibition of glial cell proinflammatory activities by peroxisome proliferator-activated receptor gamma agonist confers partial protection during antimyelin oligodendrocyte glycoprotein demyelination in vitro," Journal of Neuroscience Research, vol. 71, no. 2, pp. 246-255, 2003.

[62] B. H. Shamsi, C. Ma, S. Naqvi, and Y. Xiao, "Effects of pioglitazone mediated activation of PPAR- $\gamma$ on CIDEC and obesity related changes in mice," PLOS ONE, vol. 9, no. 9, Article ID e106992, 2014.

[63] D. Ortuño Sahagún, A. L. Márquez-Aguirre, S. QuinteroFabián, R. I. López-Roa, and A. E. Rojas-Mayorquín, "Modulation of PPAR- $\gamma$ by nutraceutics as complementary treatment for obesity-related disorders and inflammatory diseases," PPAR Research, vol. 2012, Article ID 318613, 17 pages, 2012.

[64] H. Su, W. B. Lau, and X.-L. Ma, "Hypoadiponectinaemia in diabetes mellitus type 2: molecular mechanisms and clinical significance," Clinical and Experimental Pharmacology and Physiology, vol. 38, no. 12, pp. 897-904, 2011.

[65] P. D. Storer, J. Xu, J. Chavis, and P. D. Drew, "Peroxisome proliferator-activated receptor-gamma agonists inhibit the activation of microglia and astrocytes: implications for multiple sclerosis," Journal of Neuroimmunology, vol. 161, no. 1-2, pp. 113122, 2005.

[66] C. Natarajan and J. J. Bright, "Peroxisome proliferatoractivated receptor-gamma agonists inhibit experimental allergic encephalomyelitis by blocking IL-12 production, IL-12 signaling and Th1 differentiation," Genes \& Immunity, vol. 3, no. 2, pp. 59-70, 2002.

[67] A. Coste, J.-F. Louet, M. Lagouge et al., "The genetic ablation of SRC-3 protects against obesity and improves insulin sensitivity by reducing the acetylation of PGC- $1 \alpha$," Proceedings of the National Academy of Sciences of the United States of America, vol. 105, no. 44, pp. 17187-17192, 2008.

[68] Y. Xiao, J. Xu, S. Wang et al., "Genetic ablation of steroid receptor coactivator-3 promotes PPAR- $\beta$-mediated alternative activation of microglia in experimental autoimmune encephalomyelitis," Glia, vol. 58, no. 8, pp. 932-942, 2010.

[69] W.-F. Wua, X.-J. Tana, Y.-B. Daia, V. Krishnan, M. Warner, and J.-Å. Gustafsson, "Targeting estrogen receptor $\beta$ in microglia and T cells to treat experimental autoimmune encephalomyelitis," Proceedings of the National Academy of Sciences of the United States of America, vol. 110, no. 9, pp. 3543-3548, 2013. 
[70] S. Dasgupta, M. Jana, X. Liu, and K. Pahan, "Myelin basic protein-primed $\mathrm{T}$ cells of female but not male mice induce nitric-oxide synthase and proinflammatory cytokines in microglia: implications for gender bias in multiple sclerosis," The Journal of Biological Chemistry, vol. 280, no. 38, pp. 3260932617, 2005.

[71] G. Benedek, J. Zhang, S. Bodhankar et al., "Estrogen induces multiple regulatory B cell subtypes and promotes M2 microglia and neuroprotection during experimental autoimmune encephalomyelitis," Journal of Neuroimmunology, vol. 293, pp. 45-53, 2016.

[72] L. Negrotto, M. F. Farez, and J. Correale, "Immunologic effects of metformin and pioglitazone treatment on metabolic syndrome and multiple sclerosis," JAMA Neurology, vol. 73, no. 5, pp. 520-528, 2016.

[73] P. B. Carrieri, F. Carbone, F. Perna et al., "Longitudinal assessment of immuno-metabolic parameters in multiple sclerosis patients during treatment with glatiramer acetate," Metabolism: Clinical and Experimental, vol. 64, no. 9, pp. 1112-1121, 2015.

[74] H. Ouyang, J. Cheng, Y. Zheng, and J. Du, "Role of IL-31 in regulation of Th2 cytokine levels in patients with nasal polyps," European Archives of Oto-Rhino-Laryngology, vol. 271, no. 10, pp. 2703-2709, 2014.

[75] V. Sanna, A. Di Giacomo, A. La Cava et al., "Leptin surge precedes onset of autoimmune encephalomyelitis and correlates with development of pathogenic T cell responses," The Journal of Clinical Investigation, vol. 111, no. 2, pp. 241-250, 2003.

[76] G. Frisullo, M. Mirabella, F. Angelucci et al., "The effect of disease activity on leptin, leptin receptor and suppressor of cytokine signalling-3 expression in relapsing-remitting multiple sclerosis," Journal of Neuroimmunology, vol. 192, no. 1-2, pp. 174183, 2007.

[77] H. Hsuchou, P. K. Mishra, A. J. Kastin et al., "Saturable leptin transport across the BBB persists in EAE mice," Journal of Molecular Neuroscience, vol. 51, no. 2, pp. 364-370, 2013.

[78] S. Musio, B. Gallo, S. Scabeni et al., "A key regulatory role for histamine in experimental autoimmune encephalomyelitis: disease exacerbation in histidine decarboxylase-deficient mice," Journal of Immunology, vol. 176, no. 1, pp. 17-26, 2006.

[79] K. Chatzantoni, P. Papathanassopoulos, E. Gourzoulidou, and A. Mouzaki, "Leptin and its soluble receptor in plasma of patients suffering from remitting-relapsing multiple sclerosis (MS): in vitro effects of leptin on type-1 and type- 2 cytokine secretion by peripheral blood mononuclear cells, T-cells and monocytes of MS patients," Journal of Autoimmunity, vol. 23, no. 2, pp. 169-177, 2004.

[80] S. Ouyang, H. Hsuchou, A. J. Kastin, P. K. Mishra, Y. Wang, and W. Pan, "Leukocyte infiltration into spinal cord of EAE mice is attenuated by removal of endothelial leptin signaling," Brain, Behavior, and Immunity, vol. 40, pp. 61-73, 2014.

[81] M. E. Evangelopoulos, G. Koutsis, and M. Markianos, "Serum leptin levels in treatment-naive patients with clinically isolated syndrome or relapsing-remitting multiple sclerosis," Autoimmune Diseases, vol. 2014, Article ID 486282, 6 pages, 2014.

[82] R. F. Neuteboom, E. Verbraak, J. S. A. Voerman et al., "Serum leptin levels during pregnancy in multiple sclerosis," Multiple Sclerosis, vol. 15, no. 8, pp. 907-912, 2009.

[83] R. Martín, M. Hernández, C. Córdova, and M. L. Nieto, "Natural triterpenes modulate immune-inflammatory markers of experimental autoimmune encephalomyelitis: therapeutic implications for multiple sclerosis," British Journal of Pharmacology, vol. 166, no. 5, pp. 1708-1723, 2012.
[84] L. Piccio, J. L. Stark, and A. H. Cross, "Chronic calorie restriction attenuates experimental autoimmune encephalomyelitis," Journal of Leukocyte Biology, vol. 84, no. 4, pp. 940-948, 2008.

[85] A. P. Batocchi, M. Rotondi, M. Caggiula et al., "Leptin as a marker of multiple sclerosis activity in patients treated with interferon-beta," Journal of Neuroimmunology, vol. 139, no. 1-2, pp. 150-154, 2003.

[86] F. Angelucci, M. Mirabella, M. Caggiula et al., "Evidence of involvement of leptin and IL-6 peptides in the action of interferon-beta in secondary progressive multiple sclerosis," Peptides, vol. 26, no. 11, pp. 2289-2293, 2005.

[87] E. Eftekhari, M. Etemadifar, A. Ebrahimi, and S. Baradaran, "The relation between peptide hormones and sex hormone in patients with multiple sclerosis," Iranian Journal of Neurology, vol. 12, no. 2, pp. 60-65, 2013.

[88] V. De Rosa, C. Procaccini, A. La Cava et al., "Leptin neutralization interferes with pathogenic T cell autoreactivity in autoimmune encephalomyelitis," The Journal of Clinical Investigation, vol. 116, no. 2, pp. 447-455, 2006.

[89] M. Rotondi, A. P. Batocchi, F. Coperchini et al., "Severe disability in patients with relapsing-remitting multiple sclerosis is associated with profound changes in the regulation of leptin secretion," NeuroImmunoModulation, vol. 20, no. 6, pp. 341-347, 2013.

[90] Z.-L. Chen, D.-M. Wang, J.-F. Duan, S.-Q. Wen, Y.-F. Tang, and Z.-X. Li, "Leptin enhances the release of cytokines by peripheral blood mononuclear cells from acute multiple sclerosis patients," Neuroscience Bulletin, vol. 22, no. 2, pp. 115-117, 2006.

[91] G. Frisullo, F. Angelucci, M. Mirabella et al., "Leptin enhances the release of cytokines by peripheral blood mononuclear cells from relapsing multiple sclerosis patients," Journal of Clinical Immunology, vol. 24, no. 3, pp. 287-293, 2004.

[92] A. Hietaharju, H. Kuusisto, R. Nieminen, K. Vuolteenaho, I. Elovaara, and E. Moilanen, "Elevated cerebrospinal fluid adiponectin and adipsin levels in patients with multiple sclerosis: a Finnish co-twin study," European Journal of Neurology, vol. 17, no. 2, pp. 332-334, 2010.

[93] A. Schmid, A. Hochberg, M. Berghoff et al., "Quantification and regulation of adipsin in human cerebrospinal fluid (CSF)," Clinical Endocrinology, vol. 84, no. 2, pp. 194-202, 2016.

[94] K. L. Graham, B. A. Zabel, S. Loghavi et al., "Chemokinelike receptor-1 expression by central nervous system-infiltrating leukocytes and involvement in a model of autoimmune demyelinating disease," The Journal of Immunology, vol. 183, no. 10, pp. 6717-6723, 2009.

[95] R. Lande, V. Gafa, B. Serafini et al., "Plasmacytoid dendritic cells in multiple sclerosis: intracerebral recruitment and impaired maturation in response to interferon- $\beta$," Journal of Neuropathology and Experimental Neurology, vol. 67, no. 5, pp. 388-401, 2008.

[96] M. Assadi, H. Salimipour, S. Akbarzadeh et al., "Correlation of circulating omentin-1 with bone mineral density in multiple sclerosis: the crosstalk between bone and adipose tissue," PLoS ONE, vol. 6, no. 9, Article ID e24240, 2011.

[97] P. Connick, M. Kolappan, C. Crawley et al., "Autologous mesenchymal stem cells for the treatment of secondary progressive multiple sclerosis: an open-label phase 2a proof-of-concept study," The Lancet Neurology, vol. 11, no. 2, pp. 150-156, 2012.

[98] M. Mohyeddin Bonab, M. Mohajeri, M. A. Sahraian et al., "Evaluation of cytokines in multiple sclerosis patients treated withmesenchymal stem cells," Archives of Medical Research, vol. 44, no. 4, pp. 266-272, 2013. 
[99] B. Yamout, R. Hourani, H. Salti et al., "Bone marrow mesenchymal stem cell transplantation in patients with multiple sclerosis: a pilot study," Journal of Neuroimmunology, vol. 227, no. 1-2, pp. 185-189, 2010.

[100] D. Karussis, C. Karageorgiou, A. Vaknin-Dembinsky et al., "Safety and immunological effects of mesenchymal stem cell transplantation in patients with multiple sclerosis and amyotrophic lateral sclerosis," Archives of Neurology, vol. 67, no. 10, pp. 1187-1194, 2010.

[101] Y. J. Alderazi, S. W. Coons, and K. Chapman, "Catastrophic demyelinating encephalomyelitis after intrathecal and intravenous stem cell transplantation in a patient with multiple sclerosis," Journal of Child Neurology, vol. 27, no. 5, pp. 632-635, 2012.

[102] T. Zeis, L. Enz, and N. Schaeren-Wiemers, "The immunomodulatory oligodendrocyte," Brain Research, vol. 1641, pp. 139-148, 2016.

[103] N. Scolding, R. Franklin, S. Stevens, C.-H. Heldin, A. Compston, and J. Newcombe, "Oligodendrocyte progenitors are present in the normal adult human CNS and in the lesions of multiple sclerosis," Brain, vol. 121, part 12, pp. 2221-2228, 1998.

[104] J. M. Bin, S. Rajasekharan, T. Kuhlmann et al., "Full-length and fragmented netrin-1 in multiple sclerosis plaques are inhibitors of oligodendrocyte precursor cell migration," The American Journal of Pathology, vol. 183, no. 3, pp. 673-680, 2013.

[105] M. C. Sádaba, J. Tzartos, C. Paíno et al., "Axonal and oligodendrocyte-localized IgM and IgG deposits in MS lesions," Journal of Neuroimmunology, vol. 247, no. 1-2, pp. 86-94, 2012.

[106] H. C. Wilson, N. J. Scolding, and C. S. Raine, "Co-expression of PDGF $\alpha$ receptor and NG2 by oligodendrocyte precursors in human CNS and multiple sclerosis lesions," Journal of Neuroimmunology, vol. 176, no. 1-2, pp. 162-173, 2006.

[107] N. Koning, D. F. Swaab, R. M. Hoek, and I. Huitinga, "Distribution of the immune inhibitory molecules CD200 and CD200R in the normal central nervous system and multiple sclerosis lesions suggests neuron-glia and glia-glia interactions," Journal of Neuropathology and Experimental Neurology, vol. 68, no. 2, pp. 159-167, 2009.

[108] W. Lin, S. L. Bailey, H. Ho et al., "The integrated stress response prevents demyelination by protecting oligodendrocytes against immune-mediated damage," The Journal of Clinical Investigation, vol. 117, no. 2, pp. 448-456, 2007.

[109] W. Lin, Y. Lin, J. Li et al., "Oligodendrocyte-specific activation of PERK signaling protects mice against experimental autoimmune encephalomyelitis," The Journal of Neuroscience, vol. 33, no. 14, pp. 5980-5991, 2013.

[110] Z. Liu and M. Chopp, "Astrocytes, therapeutic targets for neuroprotection and neurorestoration in ischemic stroke," Progress in Neurobiology, 2015.

[111] A. H. Cross and G. Ku, "Astrocytes and central nervous system endothelial cells do not express B7-1 (CD80) or B7-2 (CD86) immunoreactivity during experimental autoimmune encephalomyelitis," Journal of Neuroimmunology, vol. 110, no. 12, pp. 76-82, 2000.

[112] J. Correale and M. F. Farez, "The role of astrocytes in multiple sclerosis progression," Frontiers in Neurology, vol. 6, article 180, 2015.

[113] A. Viehover, R. H. Miller, S.-K. Park, G. Fischbach, and T. Vartanian, "Neuregulin: an oligodendrocyte growth factor absent in active multiple sclerosis lesions," Developmental Neuroscience, vol. 23, no. 4-5, pp. 377-386, 2001.
[114] J.-Q. Liu, J. W. Carl Jr., P. S. Joshi et al., "CD24 on the resident cells of the central nervous system enhances experimental autoimmune encephalomyelitis," Journal of Immunology, vol. 178, no. 10, pp. 6227-6235, 2007.

[115] E. H. Tran, H. Hardin-Pouzet, G. Verge, and T. Owens, "Astrocytes and microglia express inducible nitric oxide synthase in mice with experimental allergic encephalomyelitis," Journal of Neuroimmunology, vol. 74, no. 1-2, pp. 121-129, 1997.

[116] M. Godínez-Rubí, A. E. Rojas-Mayorquín, and D. OrtuñoSahagún, "Nitric oxide donors as neuroprotective agents after an ischemic stroke-related inflammatory reaction," Oxidative Medicine and Cellular Longevity, vol. 2013, Article ID 297357, 16 pages, 2013.

[117] G. Mallucci, L. Peruzzotti-Jametti, J. D. Bernstock, and S. Pluchino, "The role of immune cells, glia and neurons in white and gray matter pathology in multiple sclerosis," Progress in Neurobiology, vol. 127-128, pp. 1-22, 2015.

[118] C. Lucchinetti, W. Brück, J. Parisi, B. Scheithauer, M. Rodriguez, and H. Lassmann, "Heterogeneity of multiple sclerosis lesions: implications for the pathogenesis of demyelination," Annals of Neurology, vol. 47, no. 6, pp. 707-717, 2000.

[119] M. P. Murphy, "How mitochondria produce reactive oxygen species," The Biochemical Journal, vol. 417, no. 1, pp. 1-13, 2009.

[120] C. Wegner, M. M. Esiri, S. A. Chance, J. Palace, and P. M. Matthews, "Neocortical neuronal, synaptic, and glial loss in multiple sclerosis," Neurology, vol. 67, no. 6, pp. 960-967, 2006.

[121] S. R. Choi, O. W. Howell, D. Carassiti et al., "Meningeal inflammation plays a role in the pathology of primary progressive multiple sclerosis," Brain, vol. 135, part 10, pp. 2925-2937, 2012.

[122] Y. Liu, I. Teige, B. Birnir, and S. Issazadeh-Navikas, "Neuronmediated generation of regulatory $\mathrm{T}$ cells from encephalitogenic T cells suppresses EAE," Nature Medicine, vol. 12, no. 5, pp. 518-525, 2006.

[123] C. Severson and D. A. Hafler, "T-cells in multiple sclerosis," Results and Problems in Cell Differentiation, vol. 51, pp. 75-98, 2010.

[124] T. Naito, H. Tanaka, Y. Naoe, and I. Taniuchi, “Transcriptional control of T-cell development," International Immunology, vol. 23, no. 11, pp. 661-668, 2011.

[125] G. Martino and H.-P. Hartung, "Immunopathogenesis of multiple sclerosis: the role of T cells," Current Opinion in Neurology, vol. 12, no. 3, pp. 309-321, 1999.

[126] A. Compston and A. Coles, "Multiple sclerosis," The Lancet, vol. 359, no. 9313, pp. 1221-1231, 2002.

[127] J. D. J. Guerrero-García, V. A. Castañeda-Moreno, N. TorresCarrillo et al., "Interleukin-17A levels vary in relapsingremitting multiple sclerosis patients in association with their age, treatment and the time of evolution of the disease," NeuroImmunoModulation, vol. 23, no. 1, pp. 8-17, 2016.

[128] L. De Riccardis, A. Rizzello, A. Ferramosca et al., "Bioenergetics profile of $\mathrm{CD}^{+} \mathrm{T}$ cells in relapsing remitting multiple sclerosis subjects," Journal of Biotechnology, vol. 202, pp. 31-39, 2015.

[129] M. Strachan-Whaley, S. Rivest, and V. W. Yong, "Interactions between microglia and $\mathrm{T}$ cells in multiple sclerosis pathobiology," Journal of Interferon \& Cytokine Research, vol. 34, no. 8, pp. 615-622, 2014.

[130] Y. Okuda, M. Okuda, B. R. Apatoff, and D. N. Posnett, "The activation of memory $\mathrm{CD} 4^{+} \mathrm{T}$ cells and $\mathrm{CD} 8^{+} \mathrm{T}$ cells in patients with multiple sclerosis," Journal of the Neurological Sciences, vol. 235, no. 1-2, pp. 11-17, 2005. 
[131] L. Scandiuzzi, K. Ghosh, and X. Zang, "T cell costimulation and coinhibition: genetics and disease," Discovery Medicine, vol. 12, no. 63, pp. 119-128, 2011.

[132] S. Markovic-Plese, I. Cortese, K.-P. Wandinger, H. F. McFarland, and R. Martin, "CD4+CD28- costimulation-independent T cells in multiple sclerosis," The Journal of Clinical Investigation, vol. 108, no. 8, pp. 1185-1194, 2001.

[133] E. M. L. Oliveira, A. Bar-Or, A. I. Waliszewska et al., "CTLA-4 dysregulation in the activation of myelin basic protein reactive $\mathrm{T}$ cells may distinguish patients with multiple sclerosis from healthy controls," Journal of Autoimmunity, vol. 20, no. 1, pp. 71-81, 2003.

[134] C. Scholz, K. T. Patton, D. E. Anderson, G. J. Freeman, and D. A. Hafler, "Expansion of autoreactive T cells in multiple sclerosis is independent of exogenous B7 costimulation," The Journal of Immunology, vol. 160, no. 3, pp. 1532-1538, 1998.

[135] J.-B. Sun, T. Olsson, W.-Z. Wang et al., "Autoreactive T and $B$ cells responding to myelin proteolipid protein in multiple sclerosis and controls," European Journal of Immunology, vol. 21, no. 6, pp. 1461-1468, 1991.

[136] J. Burns, B. Bartholomew, and S. Lobo, "Isolation of myelin basic protein-specific $\mathrm{T}$ cells predominantly from the memory T-cell compartment in multiple sclerosis," Annals of Neurology, vol. 45, no. 1, pp. 33-39, 1999.

[137] Y. K. Chou, D. N. Bourdette, H. Offner et al., "Frequency of T cells specific for myelin basic protein and myelin proteolipid protein in blood and cerebrospinal fluid in multiple sclerosis," Journal of Neuroimmunology, vol. 38, no. 1-2, pp. 105-113, 1992.

[138] M. Chofflon, H. L. Weiner, C. Morimoto, and D. A. Hafler, "Decrease of suppressor inducer (CD4+2H4+) T cells in multiple sclerosis cerebrospinal fluid," Annals of Neurology, vol. 25, no. 5, pp. 494-499, 1989.

[139] C. A. Knosp and J. A. Johnston, "Regulation of CD4 ${ }^{+}$Tcell polarization by suppressor of cytokine signalling proteins," Immunology, vol. 135, no. 2, pp. 101-111, 2012.

[140] T. Renno, R. Zeine, J. M. Girard, S. Glllani, V. Dodelet, and T. Owens, "Selective enrichment of Th1 CD45RBlow CD4+ T cells in autoimmune infiltrates in experimental allergic encephalomyelitis," International Immunology, vol. 6, no. 2, pp. 347354, 1994.

[141] B. Becher, B. G. Durell, and R. J. Noelle, "Experimental autoimmune encephalitis and inflammation in the absence of interleukin-12," The Journal of Clinical Investigation, vol. 110, no. 4, pp. 493-497, 2002.

[142] H. S. Panitch, A. S. Haley, R. L. Hirsch, and K. P. Johnson, "Exacerbations of multiple sclerosis in patients treated with gamma interferon," The Lancet, vol. 329, no. 8538, pp. 893-895, 1987.

[143] C. Rohowsky-Kochan, D. Molinaro, and S. D. Cook, "Cytokine secretion profile of myelin basic protein-specific $\mathrm{T}$ cells in multiple sclerosis," Multiple Sclerosis, vol. 6, no. 2, pp. 69-77, 2000.

[144] Y. Pan and Y. Chen, "Generation and characterization of smad7 conditional knockout mice," in TGF- $\beta$ Signaling, vol. 1344 of Methods in Molecular Biology, pp. 233-243, Springer, 2016.

[145] I. Kleiter, J. Song, D. Lukas et al., "Smad7 in T cells drives $\mathrm{T}$ helper 1 responses in multiple sclerosis and experimental autoimmune encephalomyelitis," Brain, vol. 133, no. 4, pp. 10671081, 2010.

[146] A. Langer-Gould, R. Gupta, S. Huang et al., "Interferon- $\gamma$ producing $\mathrm{T}$ cells, pregnancy, and postpartum relapses of multiple sclerosis," Archives of Neurology, vol. 67, no. 1, pp. 51-57, 2010.

[147] R. A. Sosa and T. G. Forsthuber, "The critical role of antigenpresentation-induced cytokine crosstalk in the central nervous system in multiple sclerosis and experimental autoimmune encephalomyelitis," Journal of Interferon \& Cytokine Research, vol. 31, no. 10, pp. 753-768, 2011.

[148] A. Roy and K. Pahan, "Myelin basic protein-primed T helper 2 cells suppress microglial activation via AlphaVBeta3 integrin: implications for multiple sclerosis," Journal of Clinical \& Cellular Immunology, vol. 7, article 158, 2013.

[149] A. Miller, S. Shapiro, R. Gershtein et al., "Treatment of multiple sclerosis with copolymer-1 (Copaxone): implicating mechanisms of Th1 to Th2/Th3 immune-deviation," Journal of Neuroimmunology, vol. 92, no. 1-2, pp. 113-121, 1998.

[150] O. Neuhaus, C. Farina, A. Yassouridis et al., "Multiple sclerosis: comparison of copolymer-1- reactive $\mathrm{T}$ cell lines from treated and untreated subjects reveals cytokine shift from $\mathrm{T}$ helper 1 to T helper 2 cells," Proceedings of the National Academy of Sciences of the United States of America, vol. 97, no. 13, pp. 7452-7457, 2000.

[151] R. Furlan, A. Bergami, R. Lang et al., "Interferon- $\beta$ treatment in multiple sclerosis patients decreases the number of circulating $\mathrm{T}$ cells producing interferon- $\gamma$ and interleukin-4," Journal of Neuroimmunology, vol. 111, no. 1-2, pp. 86-92, 2000.

[152] R. Planas, I. Metz, Y. Ortiz et al., "Central role of Th2/Tc2 lymphocytes in pattern II multiple sclerosis lesions," Annals of Clinical and Translational Neurology, vol. 2, no. 9, pp. 875-893, 2015.

[153] T. McLaughlin, L.-F. Liu, C. Lamendola et al., "T-cell profile in adipose tissue is associated with insulin resistance and systemic inflammation in humans," Arteriosclerosis, Thrombosis, and Vascular Biology, vol. 34, no. 12, pp. 2637-2643, 2014.

[154] L. E. Harrington, R. D. Hatton, P. R. Mangan et al., "Interleukin 17-producing CD4+ effector T cells develop via a lineage distinct from the T helper type 1 and 2 lineages," Nature Immunology, vol. 6, no. 11, pp. 1123-1132, 2005.

[155] M. Noack and P. Miossec, "Th17 and regulatory T cell balance in autoimmune and inflammatory diseases," Autoimmunity Reviews, vol. 13, no. 6, pp. 668-677, 2014.

[156] V. Brucklacher-Waldert, K. Stuerner, M. Kolster, J. Wolthausen, and E. Tolosa, "Phenotypical and functional characterization of T helper 17 cells in multiple sclerosis," Brain, vol. 132, no. 12, pp. 3329-3341, 2009.

[157] M. Montes, X. Zhang, L. Berthelot et al., "Oligoclonal myelinreactive $\mathrm{T}$-cell infiltrates derived from multiple sclerosis lesions are enriched in Th17 cells," Clinical Immunology, vol. 130, no. 2, pp. 133-144, 2009.

[158] H. Kebir, K. Kreymborg, I. Ifergan et al., "Human TH17 lymphocytes promote blood-brain barrier disruption and central nervous system inflammation," Nature Medicine, vol. 13, no. 10, pp. 1173-1175, 2007.

[159] M. Kostic, T. Dzopalic, S. Zivanovic et al., "IL-17 and glutamate excitotoxicity in the pathogenesis of multiple sclerosis," Scandinavian Journal of Immunology, vol. 79, no. 3, pp. 181-186, 2014.

[160] S. Zhu and Y. Qian, "IL-17/IL-17 receptor system in autoimmune disease: mechanisms and therapeutic potential," Clinical Science, vol. 122, no. 11, pp. 487-511, 2012.

[161] J. Zepp, L. Wu, and X. Li, "IL-17 receptor signaling and T helper 17-mediated autoimmune demyelinating disease," Trends in Immunology, vol. 32, no. 5, pp. 232-239, 2011. 
[162] Y. K. Lee, H. Turner, C. L. Maynard et al., "Late developmental plasticity in the T Helper 17 lineage," Immunity, vol. 30, no. 1, pp. 92-107, 2009.

[163] K. S. Carbajal, Y. Mironova, J. T. Ulrich-Lewis et al., “Th cell diversity in experimental autoimmune encephalomyelitis and multiple sclerosis," Journal of Immunology, vol. 195, no. 6, pp. 2552-2559, 2015.

[164] L. Durelli, L. Conti, M. Clerico et al., "T-helper 17 cells expand in multiple sclerosis and are inhibited by interferon- $\beta$," Annals of Neurology, vol. 65, no. 5, pp. 499-509, 2009.

[165] V. S. Ramgolam and S. Markovic-Plese, "Interferon-beta inhibits Th17 cell differentiation in patients with multiple sclerosis," Endocrine, Metabolic \& Immune Disorders-Drug Targets, vol. 10, no. 2, pp. 161-167, 2010.

[166] X. Zhang and S. Markovic-Plese, "Interferon beta inhibits the Th17 cell-mediated autoimmune response in patients with relapsing-remitting multiple sclerosis," Clinical Neurology and Neurosurgery, vol. 112, no. 7, pp. 641-645, 2010.

[167] S. Winer, G. Paltser, Y. Chan et al., "Obesity predisposes to Th17 bias," European Journal of Immunology, vol. 39, no. 9, pp. 26292635, 2009.

[168] M. Ahmed and S. L. Gaffen, "IL-17 inhibits adipogenesis in part via $\mathrm{C} / \mathrm{EBP} \alpha$, PPAR $\gamma$ and Krüppel-like factors," Cytokine, vol. 61, no. 3, pp. 898-905, 2013.

[169] C. T. Luo and M. O. Li, "Transcriptional control of regulatory T cell development and function," Trends in Immunology, vol. 34, no. 11, pp. 531-539, 2013.

[170] M. H. Nyirenda, E. Morandi, U. Vinkemeier et al., "TLR2 stimulation regulates the balance between regulatory $\mathrm{T}$ cell and Th17 function: a novel mechanism of reduced regulatory T cell function in multiple sclerosis," Journal of Immunology, vol. 194, no. 12, pp. 5761-5774, 2015.

[171] M. J. McGeachy, L. A. Stephens, and S. M. Anderton, "Natural recovery and protection from autoimmune encephalomyelitis: contribution of $\mathrm{CD} 44^{+} \mathrm{CD} 25^{+}$regulatory cells within the central nervous system," The Journal of Immunology, vol. 175, no. 5, pp. 3025-3032, 2005.

[172] T. Schneider-Hohendorf, M.-P. Stenner, C. Weidenfeller et al., "Regulatory T cells exhibit enhanced migratory characteristics, a feature impaired in patients with multiple sclerosis," European Journal of Immunology, vol. 40, no. 12, pp. 3581-3590, 2010.

[173] J. R. Huddlestone and M. B. A. Oldstone, "Suppressor T cells are activated in vivo in patients with multiple sclerosis coinciding with remission from acute attack," Journal of Immunology, vol. 129, no. 3, pp. 915-917, 1982.

[174] E. Kouchaki, M. Salehi, M. Reza Sharif, H. Nikoueinejad, and H. Akbari, "Numerical status of $\mathrm{CD}^{+} \mathrm{CD} 25^{+} \mathrm{FoxP}^{+}$and $\mathrm{CD}^{+} \mathrm{CD} 28^{-}$regulatory $\mathrm{T}$ cells in multiple sclerosis," Iranian Journal of Basic Medical Sciences, vol. 17, no. 4, pp. 250-255, 2014.

[175] P. Praksova, P. Stourac, J. Bednarik, E. Vlckova, Z. Mikulkova, and J. Michalek, "Immunoregulatory T cells in multiple sclerosis and the effect of interferon beta and glatiramer acetate treatment on T cell subpopulations," Journal of the Neurological Sciences, vol. 319, no. 1-2, pp. 18-23, 2012.

[176] M.-A. Bach, E. Tournier, F. Phan-Dinh-Tuy et al., "Deficit of suppressor t cells in active multiple sclerosis," The Lancet, vol. 316, no. 8206, pp. 1221-1223, 1980.

[177] D. Dalla Libera, D. Di Mitri, A. Bergami et al., "T regulatory cells are markers of disease activity in multiple sclerosis patients," PLoS ONE, vol. 6, no. 6, Article ID e21386, 2011.
[178] J. Haas, M. Korporal, B. Balint, B. Fritzsching, A. Schwarz, and B. Wildemann, "Glatiramer acetate improves regulatory T-cell function by expansion of naive $\mathrm{CD} 4^{+} \mathrm{CD} 25^{+} \mathrm{FOXP} 3^{+} \mathrm{CD} 31^{+} \mathrm{T}$ cells in patients with multiple sclerosis," Journal of Neuroimmunology, vol. 216, no. 1-2, pp. 113-117, 2009.

[179] M. Chen, G. Chen, S. Deng, X. Liu, G. J. Hutton, and J. Hong, "IFN- $\beta$ induces the proliferation of $\mathrm{CD} 4^{+} \mathrm{CD} 25^{+} \mathrm{Foxp}^{+}$ regulatory T cells through upregulation of GITRL on dendritic cells in the treatment of multiple sclerosis," Journal of Neuroimmunology, vol. 242, no. 1-2, pp. 39-46, 2012.

[180] A. Namdar, B. Nikbin, M. Ghabaee, A. Bayati, and M. Izad, "Effect of IFN- $\beta$ therapy on the frequency and function of $\mathrm{CD} 4{ }^{+} \mathrm{CD} 25^{+}$regulatory $\mathrm{T}$ cells and Foxp3 gene expression in relapsing-remitting multiple sclerosis (RRMS): a preliminary study," Journal of Neuroimmunology, vol. 218, no. 1-2, pp. 120124,2010

[181] F. Palavra, L. Almeida, A. F. Ambrósio, and F. Reis, "Obesity and brain inflammation: a focus on multiple sclerosis," Obesity Reviews, vol. 17, no. 3, pp. 211-224, 2016.

[182] L. Xu, Z. Xu, and M. Xu, "Glucocorticoid treatment restores the impaired suppressive function of regulatory $T$ cells in patients with relapsing-remitting multiple sclerosis," Clinical and Experimental Immunology, vol. 158, no. 1, pp. 26-30, 2009.

[183] G. Frisullo, V. Nociti, R. Iorio et al., "Glucocorticoid treatment reduces T-bet and pSTAT1 expression in mononuclear cells from relapsing remitting multiple sclerosis patients," Clinical Immunology, vol. 124, no. 3, pp. 284-293, 2007.

[184] C. Mammi, V. Marzolla, A. Armani et al., "A novel combined glucocorticoid-mineralocorticoid receptor selective modulator markedly prevents weight gain and fat mass expansion in mice fed a high-fat diet," International Journal of Obesity, vol. 40, no. 6, pp. 964-972, 2016.

[185] K. John, J. S. Marino, E. R. Sanchez, and T. D. Hinds Jr., "The glucocorticoid receptor: cause of or cure for obesity?" American Journal of Physiology -Endocrinology and Metabolism, vol. 310, no. 4, pp. E249-E257, 2016.

[186] D. Haghmorad, A. A. Amini, M. B. Mahmoudi, M. Rastin, M. Hosseini, and M. Mahmoudi, "Pregnancy level of estrogen attenuates experimental autoimmune encephalomyelitis in both ovariectomized and pregnant C57BL/6 mice through expansion of Treg and Th2 cells," Journal of Neuroimmunology, vol. 277, no. 1-2, pp. 85-95, 2014.

[187] C. Aristimuño, R. Teijeiro, L. Valor et al., "Sex-hormone receptors pattern on regulatory T-cells: clinical implications for multiple sclerosis," Clinical and Experimental Medicine, vol. 12, no. 4, pp. 247-255, 2012.

[188] H. Offner, "Neuroimmunoprotective effects of estrogen and derivatives in experimental autoimmune encephalomyelitis: therapeutic implications for multiple sclerosis," Journal of Neuroscience Research, vol. 78, no. 5, pp. 603-624, 2004.

[189] H. Offner and M. Polanczyk, "A potential role for estrogen in experimental autoimmune encephalomyelitis and multiple sclerosis," Annals of the New York Academy of Sciences, vol. 1089, pp. 343-372, 2006.

[190] F. Lizcano and G. Guzmán, "Estrogen deficiency and the origin of obesity during menopause," BioMed Research International, vol. 2014, Article ID 757461, 11 pages, 2014.

[191] M. Salou, B. Nicol, A. Garcia, and D.-A. Laplaud, "Involvement of $\mathrm{CD}^{+} \mathrm{T}$ cells in multiple sclerosis," Frontiers in Immunology, vol. 6, article 604, 2015. 
[192] S. Sinha, A. W. Boyden, F. R. Itani, M. P. Crawford, and N. J. Karandikar, "CD8+ T-cells as immune regulators of multiple sclerosis," Frontiers in Immunology, vol. 6, article 619, 2015.

[193] V. E. Maltby, M. C. Graves, R. A. Lea et al., "Genome-wide DNA methylation profiling of $\mathrm{CD}^{+} \mathrm{T}$ cells shows a distinct epigenetic signature to $\mathrm{CD}^{+} \mathrm{T}$ cells in multiple sclerosis patients," Clinical Epigenetics, vol. 7, article 118, 2015.

[194] M. Bettini, K. Rosenthal, and B. D. Evavold, "Pathogenic MOGreactive $\mathrm{CD} 8+\mathrm{T}$ cells require MOG-reactive $\mathrm{CD} 4+\mathrm{T}$ cells for sustained CNS inflammation during chronic EAE," Journal of Neuroimmunology, vol. 213, no. 1-2, pp. 60-68, 2009.

[195] M. Camara, N. Beyersdorf, H. J. Fischer et al., "CD8 ${ }^{+}$T cell help is required for efficient induction of EAE in Lewis rats," Journal of Neuroimmunology, vol. 260, no. 1-2, pp. 17-27, 2013.

[196] M.-L. Chen, B.-S. Yan, Y. Bando, V. K. Kuchroo, and H. L. Weiner, "Latency-associated peptide identifies a novel CD4 $+\mathrm{CD} 25$ + regulatory T cell subset with TGF $\beta$-mediated function and enhanced suppression of experimental autoimmune encephalomyelitis," Journal of Immunology, vol. 180, no. 11, pp. 7327-7337, 2008.

[197] M.-L. Chen, B.-S. Yan, D. Kozoriz, and H. L. Weiner, "Novel $\mathrm{CD}^{+}$Treg suppress EAE by TGF- $\beta$ - and IFN- $\gamma$-dependent mechanisms," European Journal of Immunology, vol. 39, no. 12, pp. 3423-3435, 2009.

[198] J. Correale and A. Villa, "Role of CD8+ CD25+ Foxp3+ regulatory T cells in multiple sclerosis," Annals of Neurology, vol. 67, no. 5, pp. 625-638, 2010.

[199] G. Matarese, P. B. Carrieri, S. Montella, V. De Rosa, and A. La Cava, "Leptin as a metabolic link to multiple sclerosis," Nature Reviews Neurology, vol. 6, no. 8, pp. 455-461, 2010.

[200] M. Poggi, J. Jager, O. Paulmyer-Lacroix et al., "The inflammatory receptor CD40 is expressed on human adipocytes: contribution to crosstalk between lymphocytes and adipocytes," Diabetologia, vol. 52, no. 6, pp. 1152-1163, 2009.

[201] M. J. Neuparth, J. B. Proença, A. Santos-Silva, and S. Coimbra, "Adipokines, oxidized low-density lipoprotein, and Creactive protein levels in lean, overweight, and obese portuguese patients with type 2 diabetes," ISRN Obesity, vol. 2013, Article ID 142097, 7 pages, 2013.

[202] A. Nieva-Vazquez, R. Pérez-Fuentes, E. Torres-Rasgado, J. G. López-López, and J. R. Romero, "Serum resistin levels are associated with adiposity and insulin sensitivity in obese hispanic subjects," Metabolic Syndrome and Related Disorders, vol. 12, no. 2, pp. 143-148, 2014.

[203] X. Terra, T. Auguet, I. Quesada et al., "Increased levels and adipose tissue expression of visfatin in morbidly obese women: the relationship with pro-inflammatory cytokines," Clinical Endocrinology, vol. 77, no. 5, pp. 691-698, 2012.

[204] H. Münzberg and C. D. Morrison, "Structure, production and signaling of leptin," Metabolism: Clinical and Experimental, vol. 64, no. 1, pp. 13-23, 2015.

[205] M. Otero, R. Lago, F. Lago et al., "Leptin, from fat to inflammation: old questions and new insights," FEBS Letters, vol. 579, no. 2, pp. 295-301, 2005.

[206] K. Wåhlen, E. Sjölin, and P. Löfgren, "Role of fat cell size for plasma leptin in a large population based sample," Experimental \& Clinical Endocrinology and Diabetes, vol. 119, no. 5, pp. 291294, 2011.

[207] C. Grunfeld, C. Zhao, J. Fuller et al., "Endotoxin and cytokines induce expression of leptin, the ob gene product, in hamsters," The Journal of Clinical Investigation, vol. 97, no. 9, pp. 2152-2157, 1996.
[208] R. Faggioni, K. R. Feingold, and C. Grunfeld, "Leptin regulation of the immune response and the immunodeficiency of malnutrition," The FASEB Journal, vol. 15, no. 14, pp. 2565-2571, 2001.

[209] G. Fantuzzi and R. Faggioni, "Leptin in the regulation of immunity, inflammation, and hematopoiesis," Journal of Leukocyte Biology, vol. 68, no. 4, pp. 437-446, 2000.

[210] N. Iikuni, Q. L. K. Lam, L. Lu, G. Matarese, and A. La Cava, "Leptin and inflammation," Current Immunology Reviews, vol. 4, no. 2, pp. 70-79, 2008.

[211] I. S. Farooqi, G. Matarese, G. M. Lord et al., "Beneficial effects of leptin on obesity, $\mathrm{T}$ cell hyporesponsiveness, and neuroendocrine/metabolic dysfunction of human congenital leptin deficiency," The Journal of Clinical Investigation, vol. 110, no. 8, pp. 1093-1103, 2002.

[212] E. Papathanassoglou, K. El-Haschimi, X. C. Li, G. Matarese, T. Strom, and C. Mantzoros, "Leptin receptor expression and signaling in lymphocytes: kinetics during lymphocyte activation, role in lymphocyte survival, and response to high fat diet in mice," The Journal of Immunology, vol. 176, no. 12, pp. $7745-$ 7752, 2006.

[213] C. Martín-Romero, J. Santos-Alvarez, R. Goberna, and V. Sánchez-Margalet, "Human leptin enhances activation and proliferation of human circulating T lymphocytes," Cellular Immunology, vol. 199, no. 1, pp. 15-24, 2000.

[214] V. De Rosa, C. Procaccini, G. Calì et al., "A key role of leptin in the control of regulatory T cell proliferation," Immunity, vol. 26, no. 2, pp. 241-255, 2007.

[215] Y. Zhao, R. Sun, L. You, C. Gao, and Z. Tian, "Expression of leptin receptors and response to leptin stimulation of human natural killer cell lines," Biochemical and Biophysical Research Communications, vol. 300, no. 2, pp. 247-252, 2003.

[216] G. M. Lord, G. Matarese, J. K. Howard, S. R. Bloom, and R. I. Lechler, "Leptin inhibits the anti-CD3-driven proliferation of peripheral blood $\mathrm{T}$ cells but enhances the production of proinflammatory cytokines," Journal of Leukocyte Biology, vol. 72, no. 2, pp. 330-338, 2002.

[217] C. Lock, G. Hermans, R. Pedotti et al., "Gene-microarray analysis of multiple sclerosis lesions yields new targets validated in autoimmune encephalomyelitis," Nature Medicine, vol. 8, no. 5, pp. 500-508, 2002.

[218] Y. Yu, Y. Liu, F.-D. Shi, H. Zou, G. Matarese, and A. La Cava, "Cutting edge: leptin-induced ROR $\gamma$ t expression in $\mathrm{CD}^{+}{ }^{+} \mathrm{T}$ cells promotes Th17 responses in systemic lupus erythematosus," The Journal of Immunology, vol. 190, no. 7, pp. 3054-3058, 2013.

[219] J. Deng, Y. Liu, M. Yang et al., "Leptin exacerbates collageninduced arthritis via enhancement of Th17 cell response," Arthritis \& Rheumatism, vol. 64, no. 11, pp. 3564-3573, 2012.

[220] A. Valerio, V. Ghisi, M. Dossena et al., "Leptin increases axonal growth cone size in developing mouse cortical neurons by convergent signals inactivating glycogen synthase kinase-3 $\beta$," The Journal of Biological Chemistry, vol. 281, no. 18, pp. 1295012958, 2006.

[221] J. Udagawa, R. Hashimoto, H. Suzuki et al., "The role of leptin in the development of the cerebral cortex in mouse embryos," Endocrinology, vol. 147, no. 2, pp. 647-658, 2006.

[222] M. Galgani, C. Procaccini, V. De Rosa et al., "Leptin modulates the survival of autoreactive $\mathrm{CD}^{+} \mathrm{T}$ cells through the nutrient/energy-sensing mammalian target of rapamycin signaling pathway," Journal of Immunology, vol. 185, no. 12, pp. 7474-7479, 2010. 
[223] D. Cipolletta, M. Feuerer, A. Li et al., "PPAR- $\gamma$ is a major driver of the accumulation and phenotype of adipose tissue $\mathrm{T}_{\text {reg }}$ cells," Nature, vol. 486, no. 7404, pp. 549-553, 2012.

[224] M. Feuerer, L. Herrero, D. Cipolletta et al., "Lean, but not obese, fat is enriched for a unique population of regulatory $\mathrm{T}$ cells that affect metabolic parameters," Nature Medicine, vol. 15, no. 8, pp. 930-939, 2009.

[225] S. Winer, Y. Chan, G. Paltser et al., "Normalization of obesityassociated insulin resistance through immunotherapy," Nature Medicine, vol. 15, no. 8, pp. 921-929, 2009.

[226] V. D. Longo and L. Fontana, "Calorie restriction and cancer prevention: metabolic and molecular mechanisms," Trends in Pharmacological Sciences, vol. 31, no. 2, pp. 89-98, 2010.

[227] A. I. Esquifino, P. Cano, V. Jiménez, R. A. Cutrera, and D. P. Cardinali, "Experimental allergic encephalomyelitis in male Lewis rats subjected to calorie restriction," Journal of Physiology and Biochemistry, vol. 60, no. 4, pp. 245-252, 2004.

[228] E. Toussirot, D. Binda, C. Gueugnon, and G. Dumoulin, "Adiponectin in autoimmune diseases," Current Medicinal Chemistry, vol. 19, no. 32, pp. 5474-5480, 2012.

[229] G. Fantuzzi, "Adiponectin in inflammatory and immunemediated diseases," Cytokine, vol. 64, no. 1, pp. 1-10, 2013.

[230] J. Thundyil, D. Pavlovski, C. G. Sobey, and T. V. Arumugam, "Adiponectin receptor signalling in the brain," British Journal of Pharmacology, vol. 165, no. 2, pp. 313-327, 2012.

[231] N. Ouchi and K. Walsh, "A novel role for adiponectin in the regulation of inflammation," Arteriosclerosis, Thrombosis, and Vascular Biology, vol. 28, no. 7, pp. 1219-1221, 2008.

[232] T. Yokota, K. Oritani, I. Takahashi et al., "Adiponectin, a new member of the family of soluble defense collagens, negatively regulates the growth of myelomonocytic progenitors and the functions of macrophages," Blood, vol. 96, no. 5, pp. 1723-1732, 2000.

[233] J. Yang, S.-C. Lin, G. Chen et al., "Adiponectin promotes monocyte-to-fibroblast transition in renal fibrosis," Journal of the American Society of Nephrology, vol. 24, no. 10, pp. 16441659, 2013.

[234] K. Makki, P. Froguel, and I. Wolowczuk, "Adipose tissue in obesity-related inflammation and insulin resistance: cells, cytokines, and chemokines," ISRN Inflammation, vol. 2013, Article ID 139239, 12 pages, 2013.

[235] M. Y. Jung, H.-S. Kim, H.-J. Hong, B.-S. Youn, and T. S. Kim, "Adiponectin induces dendritic cell activation via PLC $\gamma /$ JNK/NF- $\kappa$ B pathways, leading to Th1 and Th17 polarization," Journal of Immunology, vol. 188, no. 6, pp. 2592-2601, 2012.

[236] S. Arai, N. Maehara, Y. Iwamura et al., "Obesity-associated autoantibody production requires AIM to retain the immunoglobulin $\mathrm{M}$ immune complex on follicular dendritic cells," Cell Reports, vol. 3, no. 4, pp. 1187-1198, 2013.

[237] T. Miyazaki, Y. Hirokami, N. Matsuhashi, H. Takatsuka, and M. Naito, "Increased susceptibility of thymocytes to apoptosis in mice lacking AIM, a novel murine macrophage-derived soluble factor belonging to the scavenger receptor cysteine-rich domain superfamily," The Journal of Experimental Medicine, vol. 189, no. 2, pp. 413-422, 1999.

[238] M. Haluzik and D. Haluzikova, "The role of resistin in obesityinduced insulin resistance," Current Opinion in Investigational Drugs, vol. 7, no. 4, pp. 306-311, 2006.

[239] H. S. Jung, K.-H. Park, Y. M. Cho et al., "Resistin is secreted from macrophages in atheromas and promotes atherosclerosis," Cardiovascular Research, vol. 69, no. 1, pp. 76-85, 2006.
[240] B. Gencer, R. Auer, N. de Rekeneire et al., "Association between resistin levels and cardiovascular disease events in older adults: the health, aging and body composition study," Atherosclerosis, vol. 245, pp. 181-186, 2016.

[241] Q. Huang, S.-S. Tao, Y.-J. Zhang et al., "Serum resistin levels in patients with rheumatoid arthritis and systemic lupus erythematosus: a meta-analysis," Clinical Rheumatology, vol. 34, no. 10, pp. 1713-1720, 2015.

[242] C. M. Steppan, S. T. Bailey, S. Bhat et al., "The hormone resistin links obesity to diabetes," Nature, vol. 409, no. 6818, pp. 307-312, 2001.

[243] R. Nogueiras, R. Gallego, O. Gualillo et al., "Resistin is expressed in different rat tissues and is regulated in a tissue- and genderspecific manner," FEBS Letters, vol. 548, no. 1-3, pp. 21-27, 2003.

[244] B. A. Morash, E. Ur, G. Wiesner, J. Roy, and M. Wilkinson, "Pituitary resistin gene expression: effects of age, gender and obesity," Neuroendocrinology, vol. 79, no. 3, pp. 149-156, 2004.

[245] E. Badoer, S. Kosari, and M. J. Stebbing, "Resistin, an adipokine with non-generalized actions on sympathetic nerve activity," Frontiers in Physiology, vol. 6, article 321, 2015.

[246] J. Stastny, J. Bienertova-Vasku, and A. Vasku, "Visfatin and its role in obesity development," Diabetes \& Metabolic Syndrome, vol. 6, no. 2, pp. 120-124, 2012.

[247] A. Fukuhara, M. Matsuda, M. Nishizawa et al., "Visfatin: a protein secreted by visceral fat that mimics the effects of insulin," Science, vol. 307, no. 5708, pp. 426-430, 2005.

[248] A. R. Moschen, A. Kaser, B. Enrich et al., "Visfatin, an adipocytokine with proinflammatory and immunomodulating properties," The Journal of Immunology, vol. 178, no. 3, pp. 17481758, 2007.

[249] J. P. Bao, W. P. Chen, and L.-D. Wu, "Visfatin: a potential therapeutic target for rheumatoid arthritis," The Journal of International Medical Research, vol. 37, no. 6, pp. 1655-1661, 2009.

[250] M. R. Kazemi, C. M. McDonald, J. K. Shigenaga, C. Grunfeld, and K. R. Feingold, "Adipocyte fatty acid-binding protein expression and lipid accumulation are increased during activation of murine macrophages by toll-like receptor agonists," Arteriosclerosis, Thrombosis, and Vascular Biology, vol. 25, no. 6, pp. 1220-1224, 2005.

[251] J. Jin, D.-Q. Peng, S.-G. Yuan et al., "Serum adipocyte fatty acid binding proteins and adiponectin in patients with coronary artery disease: the significance of A-FABP/adiponectin ratio," Clinica Chimica Acta, vol. 411, no. 21-22, pp. 1761-1765, 2010.

[252] J. L. Miner, J. C. Byatt, C. A. Baile, and G. G. Krivi, "Adipsin expression and growth in rats as influenced by insulin and somatotropin," Physiology \& Behavior, vol. 54, no. 2, pp. 207212, 1993.

[253] J. C. Lo, S. Ljubicic, B. Leibiger et al., "Adipsin is an adipokine that improves $\beta$ cell function in diabetes," Cell, vol. 158, no. 1, pp. 41-53, 2014.

[254] R. Natarajan, S. Hagman, M. Hämälainen et al., "Adipsin is associated with multiple sclerosis: a follow-up study of adipokines," Multiple Sclerosis International, vol. 2015, Article ID 371734, 9 pages, 2015.

[255] F. Mariani and L. Roncucci, "Chemerin/chemR23 axis in inflammation onset and resolution," Inflammation Research, vol. 64, no. 2, pp. 85-95, 2014.

[256] V. Wittamer, J.-D. Franssen, M. Vulcano et al., "Specific recruitment of antigen-presenting cells by chemerin, a novel processed ligand from human inflammatory fluids," The Journal of Experimental Medicine, vol. 198, no. 7, pp. 977-985, 2003. 
[257] K. L. Graham, J. V. Zhang, S. Lewén et al., "A novel CMKLR1 small molecule antagonist suppresses CNS autoimmune inflammatory disease," PLoS ONE, vol. 9, no. 12, article el12925, 2014.

[258] J.-Y. Zhou, L. Chan, and S.-W. Zhou, "Omentin: linking metabolic syndrome and cardiovascular disease," Current Vascular Pharmacology, vol. 12, no. 1, pp. 136-143, 2014.

[259] R.-Z. Yang, M.-J. Lee, H. Hu et al., "Identification of omentin as a novel depot-specific adipokine in human adipose tissue: possible role in modulating insulin action," American Journal of Physiology-Endocrinology and Metabolism, vol. 290, no. 6, pp. E1253-E1261, 2006.

[260] C. M. de Souza Batista, R.-Z. Yang, M.-J. Lee et al., "Omentin plasma levels and gene expression are decreased in obesity," Diabetes, vol. 56, no. 6, pp. 1655-1661, 2007.

[261] B.-S. Youn, N. Klöting, J. Kratzsch et al., "Serum vaspin concentrations in human obesity and type 2 diabetes," Diabetes, vol. 57, no. 2, pp. 372-377, 2008.

[262] J. D. Glenn and K. A. Whartenby, "Mesenchymal stem cells: emerging mechanisms of immunomodulation and therapy," World Journal of Stem Cells, vol. 6, no. 5, pp. 526-539, 2014.

[263] F. Yousefi, M. Ebtekar, M. Soleimani, S. Soudi, and S. M. Hashemi, "Comparison of in vivo immunomodulatory effects of intravenous and intraperitoneal administration of adiposetissue mesenchymal stem cells in experimental autoimmune encephalomyelitis (EAE)," International Immunopharmacology, vol. 17, no. 3, pp. 608-616, 2013.

[264] X. Zhang, A. C. Bowles, J. A. Semon et al., “Transplantation of autologous adipose stem cells lacks therapeutic efficacy in the experimental autoimmune encephalomyelitis model," PLoS ONE, vol. 9, no. 1, article e85007, 2014.

[265] C. Marin-Bañasco, M. Suardiaz García, I. Hurtado Guerrero et al., "Mesenchymal properties of SJL mice-stem cells and their efficacy as autologous therapy in a relapsing-remitting multiple sclerosis model," Stem Cell Research \& Therapy, vol. 5, no. 6, article 134, 2014.

[266] A. L. Strong, A. C. Bowles, R. M. Wise et al., "Human adipose stromal/stem cells from obese donors show reduced efficacy in halting disease progression in the experimental autoimmune encephalomyelitis model of multiple sclerosis," Stem Cells, vol. 34, no. 3, pp. 614-626, 2016. 


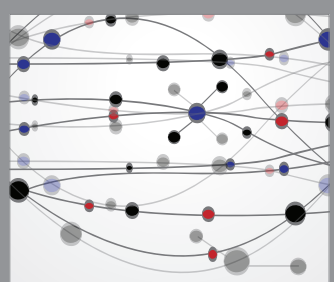

The Scientific World Journal
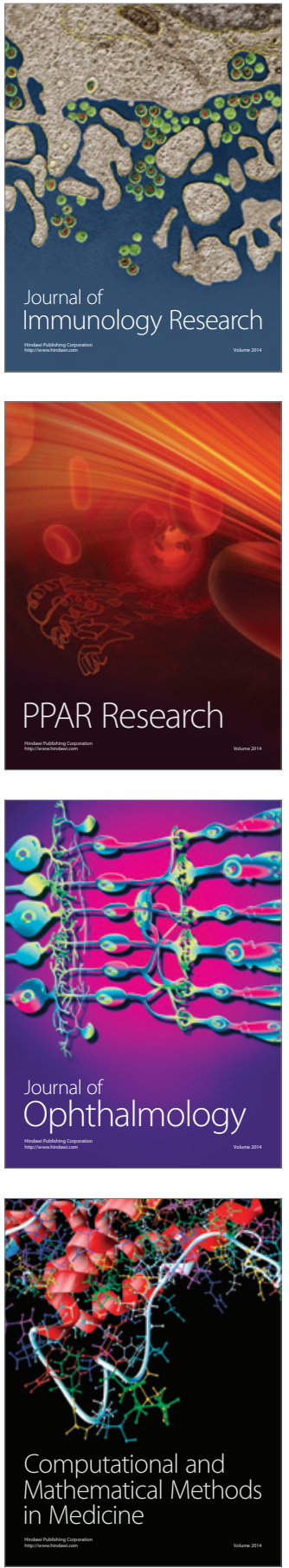

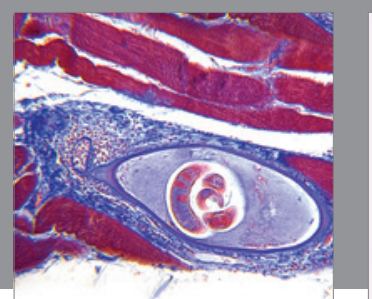

Gastroenterology Research and Practice

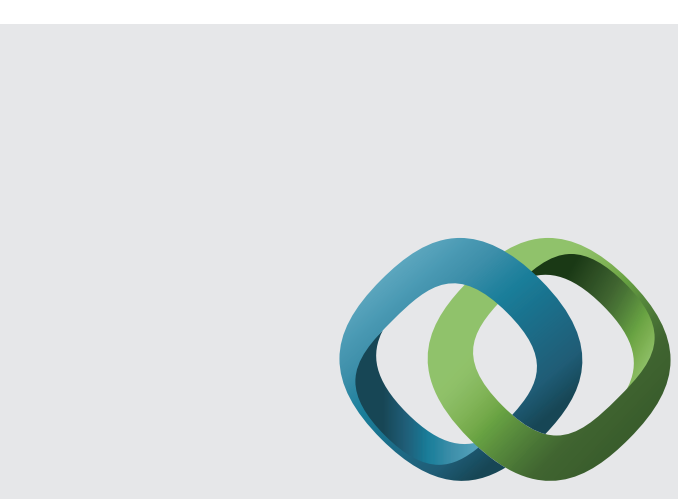

\section{Hindawi}

Submit your manuscripts at

http://www.hindawi.com
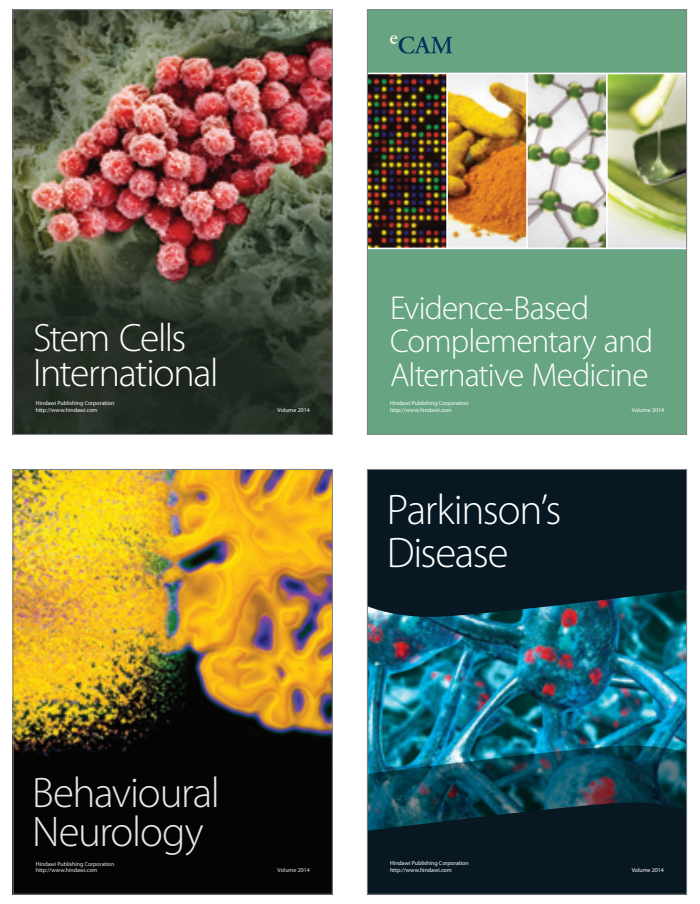
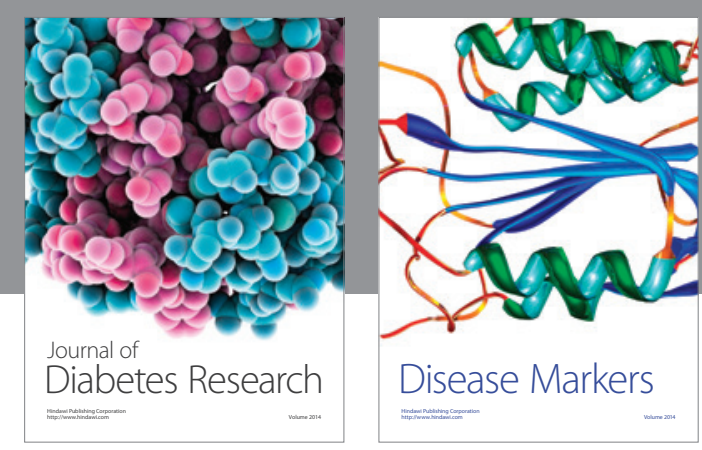

Disease Markers
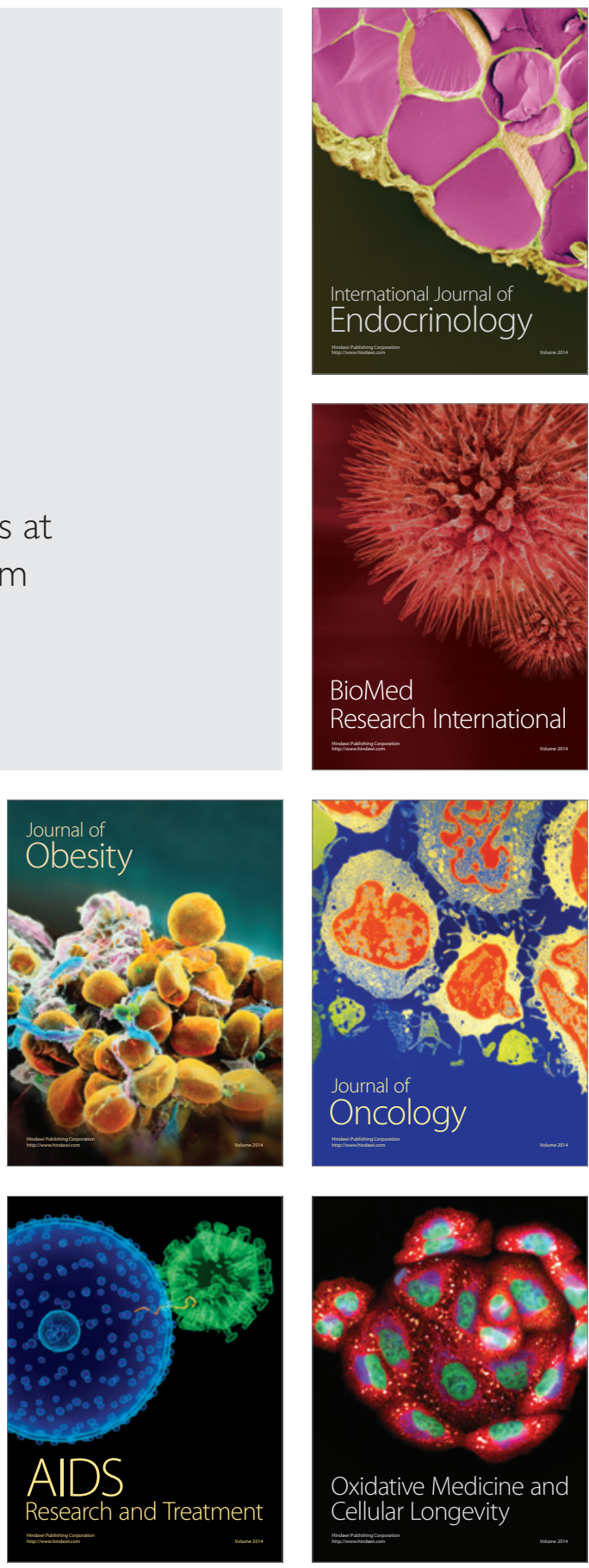